\title{
Advanced molecular-based surveillance of quagga and zebra mussels: A review of environmental DNA/RNA (eDNA/eRNA) studies and considerations for future directions
}

\author{
Sheena M. Feist', Richard F. Lance' \\ I Environmental Lab, United States Army Corps of Engineers Research and Development Center, Vicksburg, \\ MS 39180, USA
}

Corresponding author: Sheena Feist (sheena.m.feist@erdc.dren.mil)

Academic editor: A. Petrusek | Received 13 November 2020 | Accepted 22 June 2021 | Published 13 July 2021

Citation: Feist SM, Lance RF (2021) Advanced molecular-based surveillance of quagga and zebra mussels: A review of environmental DNA/RNA (eDNA/eRNA) studies and considerations for future directions. NeoBiota 66: 117-159. https://doi.org/10.3897/neobiota.66.60751

\begin{abstract}
Sensitive methods, capable of rapidly and accurately detecting aquatic invasive species, are in demand. Molecular-based approaches, such as environmental DNA (eDNA) surveys, satisfy these requirements and have grown in popularity. As such, eDNA surveys could aid the effort to combat the colonisation and spread of two notoriously invasive freshwater mussel species, the quagga mussel (Dreissena rostriformis bugensis) and zebra mussel (D. polymorpha), through improved surveillance ability. Here, we provide a review of dreissenid eDNA literature (both grey and published), summarising efforts involved in the development of various assays for use in multiple different technologies (e.g. quantitative PCR, high-throughput sequencing and loop-mediated isothermal amplification) and sampling scenarios. We discuss important discoveries made along the way, including novel revelations involving environmental RNA (eRNA), as well as the advantages and limitations of available methods and instrumentation. In closing, we highlight critical remaining gaps, where further investigation could lead to advancements in dreissenid monitoring capacity.
\end{abstract}

\section{Keywords}

Assay, ddPCR, HTS, LAMP, metabarcoding, nuclear DNA, qPCR, veligers 


\section{Introduction}

Quagga (Dreissena rostriformis bugensis) and zebra (D. polymorpha) mussels are aquatic invasive species (AIS), known for imposing costly economic and ecological damage (Higgins and Zanden 2010; Nalepa and Schloesser 2013). These mussels belong to a phylogenetically complex genus composed of at least six species (Rosenberg and Ludyanskiy 1994; Gelembiuk et al. 2006; Son 2007; Graf and Cummings 2019). Although native to the Ponto-Caspian, quagga and zebra mussels (referred to herein as QM-ZM) have become problematic invaders in North America and Europe (Karatayev et al. 2007, 2015; Ram and Palazzolo 2008; Nalepa and Schloesser 2013; Matthews et al. 2014). They possess several attributes that have contributed to their invasion success. Attributes include prolific reproduction in which microscopic floating larvae (veligers) are released into the water column and easily bypass visual detection (Johnson and Padilla 1996; Stoeckel et al. 1997), secretion of byssal threads that allow firm attachment to numerous types of substrates and infrastructures (Berkman et al. 2000; Peyer et al. 2009), broad thermal tolerance (Locklin et al. 2020) and the ability to withstand transport, drying, low oxygen levels and minimal food conditions (Kinzelbach 1992; Ricciardi et al. 1995; Baines et al. 2007; Snider et al. 2014; Doll 2018). Their accidental introduction into the Great Lakes of North America most likely occurred via transoceanic ships (specifically, ballast water discharge), with ZM first observed in 1988 (Lake St. Clair; Hebert et al. 1989) and QM in 1992 (Lake Ontario; May and Marsden 1992). Since then, populations of QM-ZM have spread throughout much of the United States (US) and south-central to south-eastern Canada through contiguous waterways, though overland human transport has also contributed to introductions in disjunct locations (Johnson and Carlton 1996; Johnson et al. 2001, 2006).

In 2007, QM-ZM were detected for the first time in the western US within three lakes of the Colorado River Basin. This discovery - and others like it (e.g. QM-ZM detections near the headwaters of the Columbia River Basin in 2016) - indicated a westward extension of the North American invasion front and led to the development of several initiatives aimed at preventing, containing and controlling the continued spread of QM-ZM. Initiatives included the Quagga-Zebra Mussel Action Plan for Western Waters of 2010 (QZAP 2010), the 100 $0^{\text {th }}$ Meridian Initiative of 2011 (United States Fish and Wildlife Service 2011) and the Safeguarding the West Initiative of 2017 (United States Department of Interior 2017). These initiatives increased coordination and standardisation of preventative measures, actions, protocols and policies across different jurisdictions and agencies (including at the National, Federal, State and Tribal levels), with input from multiple stakeholders. All initiatives called for an increase in strategic surveillance, including proactive monitoring of high-risk water bodies. In the most recent initiative, environmental DNA (eDNA) surveys were listed as priority QM-ZM monitoring actions, hypothesised to improve surveillance through increased probability of early detection (United States Department of Interior 2017).

Environmental DNA is a term commonly used to describe genetic material deposited or shed into the environment by living organisms and can include both extracel- 
lular and intracellular DNA (Ficetola 2008; Jerde et al. 2011; Thomsen and Willerslev 2015). In its broadest definition, eDNA can also encompass DNA in the form of whole microscopic organisms (e.g. bacteria, viruses, phytoplankton, QM-ZM veligers) captured during environmental sampling (Pawlowski et al. 2020). The steps involved in an eDNA survey typically include: 1) sampling a habitat of interest (commonly, freshwaters or marine waters) where a target species is suspected to be present or has the potential to be present and then 2) subjecting the collected sample to sensitive molecular assays, specifically designed to detect DNA from the target species, if present. These assays are typically based on polymerase chain reaction (PCR), with accuracy of detection often subsequently confirmed via standard Sanger DNA sequencing of all, or a subset of, resultant PCR products. With eDNA, the accurate and reliable detection of a specific organism (i.e. detection confidence) requires adherence to quality assurance-quality control (QA-QC) measures, as well as the use of rigorously vetted, high-quality assays. Detailed discussions outlining necessary QA-QC for eDNA-based surveillance efforts, as well as guidelines for developing and validating eDNA assays, are available in Goldberg et al. (2016) and Klymus et al. (2020a).

The ability to detect and/or identify organisms within an environmental sample, as based solely on the DNA within that sample, is not new. In fact, eDNA techniques have been used in microbial and ancient DNA studies for more than two decades (for reviews, see Pawlowski et al. 2020 and Pedersen et al. 2015, respectively). The application of eDNA sampling for AIS surveillance purposes is, however, comparatively younger. It made its debut as a novel technique in 2008, when pond water eDNA samples proved useful for detecting invasive American bull frogs (Lithobates catesbeianus; Ficetola et al. 2008). Since then, eDNA sampling has been widely adopted as an AIS monitoring tool, often outperforming traditional survey methods for hard-to-detect aquatic species, including QM-ZM (e.g. De Ventura et al. 2017; Gingera et al. 2017; Sepulveda et al. 2019; Blackman et al. 2020a).

The genetic material of interest in most molecular-based surveys is DNA. Similar methods targeting RNA (eRNA) are emerging, however, with particular emphasis in ballast/bilge water AIS surveillance (e.g. Pochon et al. 2017). Recent QM-ZM evidence (Marshall et al. 2021) notably supports hypotheses (Barnes and Turner 2016; Cristescu 2019) that at least certain types of RNA degrade faster than DNA in environmental matrices. As such, eRNA may be an appealing complement to eDNA in that it potentially offers enhanced discrimination between AIS detections originating from contemporary sources (i.e. live/very recently alive, locally-present organisms) and AIS detections resulting from relictual, non-local or transient sources. Regardless of target (DNA vs. RNA), molecular-based surveys are extremely sensitive (e.g. lower limits of qPCR detection for QM-ZM can be as low as three gene copies per $\mu \mathrm{l}$; Sepulveda et al. 2020a) and capable of detecting even minute amounts of target DNA/RNA. While this makes them susceptible to potential contamination (i.e. false positive detections), we reiterate that high-quality assays and careful adherence to QA-QC measures (in the field and in the lab) ensures detection confidence. Resultant robust specificity and sensitivity make molecular-based surveys particularly useful along invasion fronts 
where QM-ZM abundance may be low. Early detections play a critical role in QM$\mathrm{ZM}$ management, increasing the probability of eradication and, thereby, helping to prevent spread (Wimbush et al. 2009; Counihan and Bollens 2017).

Various molecular-based technologies and protocols have been employed in QM$\mathrm{ZM}$ eDNA surveys and numerous publications exist detailing those efforts. Improvements in eDNA methods have been made along the way to overcome the challenges presented by complex and impure environmental samples. Methodological improvements include refined protocols for isolation and extraction of eDNA, enhanced reagents to combat PCR inhibition and more stringent primer design requirements (Wilcox et al. 2013; Hinlo et al. 2017; Lance and Guan 2020). Additionally, improved methods using highly sensitive platforms like quantitative PCR (qPCR), droplet digital PCR (ddPCR), high-throughput sequencing (HTS) and field-portable machines have been developed, allowing for the quantification, massive parallel sequencing and rapid-onsite surveillance of eDNA, respectively. While each approach provides some level of detection precision for QM-ZM eDNA (i.e. taking into consideration rates of imperfect, or false positive/false negative, detections) and, thus, some level of reliable inference as to the likely presence of QM-ZM, there are advantages/disadvantages that make each approach more suitable for different applications, questions and/or sampling schemes. As such, a review of the current knowledge and a synthesis of information regarding these various methods is needed.

Here, we provide a review of QM-ZM eDNA literature, discussing how knowledge (Table 1) and methodology has evolved over time (Fig. 1). We close by discussing critical scientific and applied gaps, which require additional attention or investigation to advance molecular-based QM-ZM surveillance and inferences therein. The review is intended for eDNA practitioners of all levels. It is consequently written to be understood by large audiences, including non-molecular experts (e.g. AIS managers) interested in implementing eDNA surveys. To aid readership understanding, we have provided a glossary of terms and common eDNA approaches (Table 2).

\section{Studies to date}

In this section, we cover the history of the development and use of molecular-based methods for detecting the likely presence of QM-ZM in a sampled water body. The section is largely organised by technology type, with one sub-section dedicated to types of molecular targets (including eDNA vs. eRNA). The order follows the general progression in QM-ZM eDNA techniques, including associated advancements in eDNA knowledge and/or eDNA sampling methods.

Literature cited and reviewed was acquired in two ways. On 8 May 2020, we performed a Google Scholar search for relevant literature, using the following key words in combination with "quagga mussel", "zebra mussel" and/or "Dreissena": ddPCR, eDNA, environmental DNA, HTS, metabarcoding, NGS, PCR, qPCR, RNA. On 21 May 2020, we submitted a request for literature (to include unpublished documents and/or grey literature) from members of the Government eDNA Working Group 
Table I. Summarised findings and important highlights from the reviewed quagga mussel and zebra mussel (QM-ZM) environmental DNA (eDNA) literature, demonstrating the evolution of eDNA methods and knowledge over time. We focus on insights gained via qPCR and HTS, as these two technologies have dominated QM-ZM eDNA endeavours and provided the vast amount of advancements.

\begin{tabular}{|c|c|c|}
\hline Citation & Type & Significant findings and other highlights \\
\hline Tucker (2014) & qPCR & $\begin{array}{l}\text { - Optimisation of extraction methods needed } \\
\text { - Species-specific primers need developed }\end{array}$ \\
\hline $\begin{array}{l}\text { Bollens et al. } \\
(2015)\end{array}$ & qPCR & - qPCR multiplexing may negatively impact detection sensitivity, indicating importance of optimisation \\
\hline $\begin{array}{l}\text { Peńarrubia et } \\
\text { al. (2016) }\end{array}$ & qPCR & $\begin{array}{l}\text { - Autumn sampling increases detection success, likely as a result of high veliger presence following spring- } \\
\text { summer reproductive season } \\
\text { - Levels of infestation can be estimated using qPCR }\end{array}$ \\
\hline $\begin{array}{l}\text { Amberg and } \\
\text { Merkes (2016); } \\
\text { Amberg et al. } \\
(2019)\end{array}$ & qPCR & $\begin{array}{l}\text { - Designed } 1 \text { ZM-specific COI assay, where primers are QM-ZM generic, but probe is ZM-specific, with } \\
\text { specificity of assay tested against } 27 \text { non-target taxa } \\
\text { - Detection success increased when eDNA sampling occurred at greater depths and above soft substrates }\end{array}$ \\
\hline $\begin{array}{l}\text { Gingera et al. } \\
(2017)\end{array}$ & qPCR & $\begin{array}{l}\text { - Designed } 3 \text { assays: } 2 \text { ZM-specific (CytB and COI), } 1 \text { QM-ZM generic (16S), with specificity of assays } \\
\text { tested against } 10 \text { non-target species } \\
\text { - } \text { qPCR multiplexing negatively impacts sensitivity } \\
\text { - Autumn sampling increases detection success perhaps due to spawning activity aftermath (veliger } \\
\text { presence) } \\
\text { - Spring sampling decreases detection success potentially due to winter QM-ZM die off and increased } \\
\text { dilution from snow-melt }\end{array}$ \\
\hline $\begin{array}{l}\text { DeVentura et } \\
\text { al. (2017) }\end{array}$ & $\begin{array}{l}\text { cPCR, } \\
\text { qPCR }\end{array}$ & $\begin{array}{l}\text { - Similar performance of qPCR and conventional PCR (cPCR), but with cPCR potentially being less } \\
\text { susceptible to false positives (due to low sensitivity) } \\
\text { - eDNA concentration in field samples correlate well with known mussel densities using qPCR } \\
\text { - Recommended mesocosm experimentation to better understand how environmental variables and veliger } \\
\text { presence influence eDNA concentration estimations }\end{array}$ \\
\hline $\begin{array}{l}\text { Sepulveda et al. } \\
(2019)\end{array}$ & qPCR & $\begin{array}{l}\text { - Multi-scale occupancy modelling indicated that a high probability of detection was possible with eDNA } \\
\text { surveys, regardless of season, when substantial and adequate sampling efforts were undertaken (14 to } 34 \\
\text { replicates per eDNA site, depending on season) } \\
\text { - Summer sampling proved the most efficient and required the fewest replicates to achieve high probability } \\
\text { of detection (likely due to spawning) }\end{array}$ \\
\hline $\begin{array}{l}\text { Shogren et al. } \\
\text { (2019) }\end{array}$ & qPCR & $\begin{array}{l}\text { - Environmental variables, as well as eDNA shed and decay rates, complicate qPCR-based estimations of } \\
\text { biomass/abundance }\end{array}$ \\
\hline $\begin{array}{l}\text { Sepulveda et al. } \\
\text { (2020a) }\end{array}$ & qPCR & $\begin{array}{l}\text { - Round robin comparison of } 5 \text { QM-ZM-specific probe-based qPCR assays revealed high reproducibility } \\
\text { and repeatability (i.e. reliability) in results across different eDNA labs, with the best performing assay } \\
\text { identified as DRE16S (QM-ZM specific, Gingera et al. 2017) and with DRE2 (ZM-specific, Amberg et } \\
\text { al. 2019) identified as potentially susceptible to false negatives } \\
\text { - Cautioned against estimating biomass, based on qPCR results; estimated DNA concentrations were } \\
\text { imprecise and inaccurate in spiked samples }\end{array}$ \\
\hline $\begin{array}{l}\text { Marshall et al. } \\
(2021)\end{array}$ & qPCR & $\begin{array}{l}\text { - Ratio of eDNA:eRNA useful for assessing time since deposition in controlled aquaria settings } \\
\text { - mRNA H2B represents a useful target for assessing recent }(<24 \mathrm{~h}) \text { presence of live QM-ZM } \\
\text { - Multi-copy } 16 \mathrm{~S} \text { and } 18 \mathrm{~S} \text { rRNA represent useful targets for detecting low density QM-ZM } \\
\text { - Suggested observed patterns may be more complex in natural environments }\end{array}$ \\
\hline $\begin{array}{l}\text { Blackman et al. } \\
\text { (2020a) }\end{array}$ & $\begin{array}{l}\text { cPCR, } \\
\text { qPCR, } \\
\text { HTS }\end{array}$ & $\begin{array}{l}\text { - Detection success was greatest with cPCR and qPCR, but with all DNA-based methods outperforming } \\
\text { kick-net sampling (caveat: HTS utilised a universal metabarcoding primer not specific to QM-ZM) } \\
\text { - QM-ZM density and sampling distance impacts detection in eDNA surveillance efforts }\end{array}$ \\
\hline $\begin{array}{l}\text { Klymus et al. } \\
(2017)\end{array}$ & HTS & $\begin{array}{l}\text { - Mollusc-specific } 16 \mathrm{~S} \text { metabarcode designed } \\
\text { - HTS-based detection outperformed traditional surveys } \\
\text { - HTS read counts correlated well with initial DNA concentrations within mock community samples, } \\
\text { indicating potential utility for estimating biomass in eDNA samples using HTS methods }\end{array}$ \\
\hline $\begin{array}{l}\text { Prie et al. } \\
(2020)\end{array}$ & HTS & - Bivalve-specific $16 \mathrm{~S}$ metabarcode designed \\
\hline $\begin{array}{l}\text { Marshall and } \\
\text { Stepien (2019) }\end{array}$ & HTS & $\begin{array}{l}\text { - QM-ZM specific COI metabarcode designed } \\
\text { - Methods allowed for discrimination of QM-ZM, as well as assessments of relative abundance and genetic } \\
\text { diversity } \\
\text { - Aquaria trials indicated that biomass estimates were most accurate after QM-ZM had occupied tanks for } \\
7-14 \text { days } \\
\text { - QM-ZM biomass may be best estimated when eDNA samples are collected near the bottom of a } \\
\text { waterbody }\end{array}$ \\
\hline
\end{tabular}




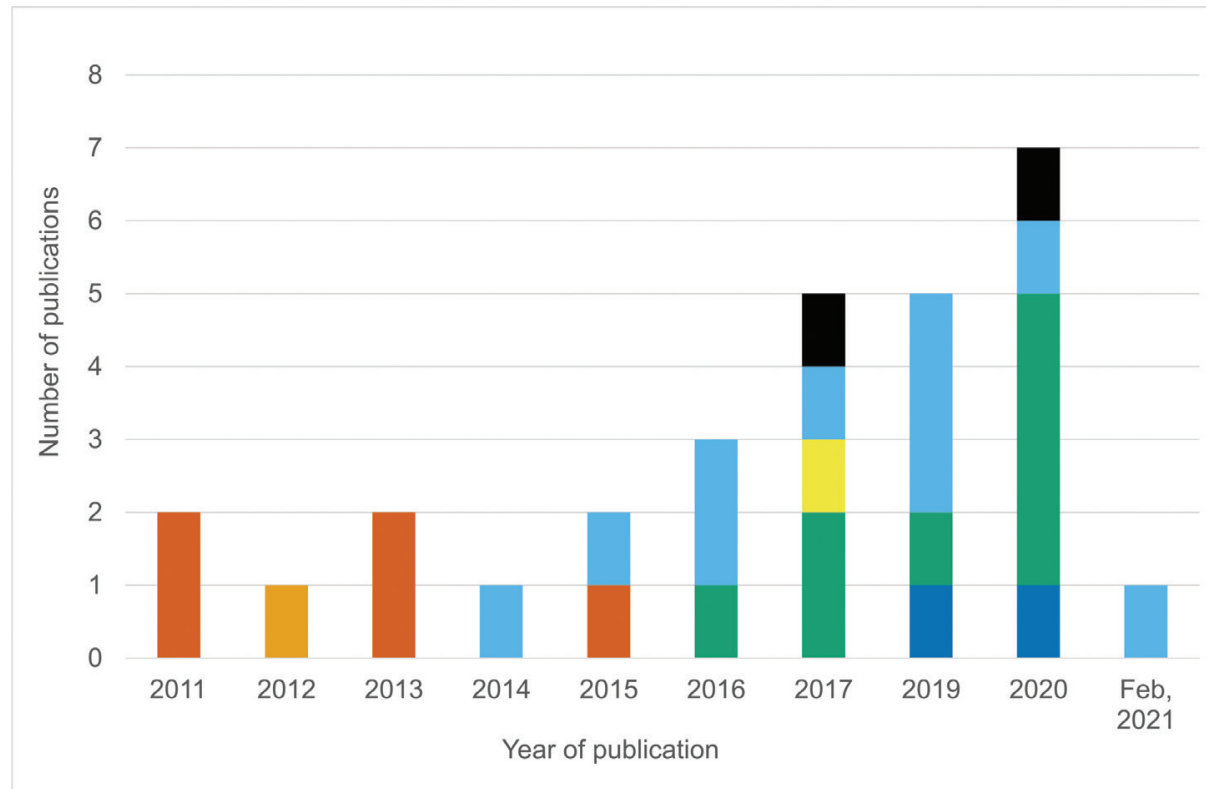

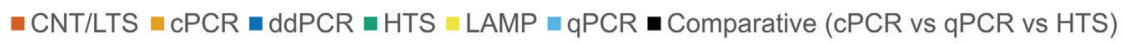

Figure I. Evolution of quagga mussel and zebra mussel (QM-ZM) environmental DNA methods through time. Numerous technologies have been used to amplify and detect the DNA of QM-ZM contained within environmental samples. Technology types include nanoparticle-based methods (i.e. carbon nanotube or light transmission spectroscopy, CNT/LTS), conventional PCR (cPCR), droplet digital PCR (ddPCR), high-throughput sequencing (HTS), loop-mediated amplification (LAMP), quantitative PCR (qPCR) and comparative methods. Here, we can see that methods have evolved over time, with qPCR and HTS currently dominating the field and with ddPCR emerging.

(GEDWG). This North American-based working group is comprised of eDNA practitioners from federal, state, local and non-government institutions (e.g. universities), several of whom have conducted QM-ZM eDNA studies. In total, 23 documents were acquired from both avenues and included in this review.

\section{Early DNA studies using whole specimens}

Molecular-based approaches have aided the effort to combat the colonisation and spread of QM-ZM by providing a mechanism for sensitive and reliable early detection. Initial endeavours began with a focus on the molecular identification of, and assessment of genetic diversity within, whole QM-ZM specimens collected from infested waters. Methods are reviewed in Marsden et al. (1996), but in short, these early studies used PCR-free, electrophoresis-based analyses (i.e. allozymes) to individually discriminate amongst morphologically similar (and sometimes unidentified) adult QM-ZM, most commonly collected via trawling. Soon after, conventional PCR-based 
Table 2. Glossary of terms relevant to (and explained specifically for) environmental DNA (eDNA) applications. Terms are grouped according to different molecular targets, sources of DNA and technology types. Terms relevant to the validation of eDNA methods and common eDNA challenges are also provided.

\begin{tabular}{|c|c|}
\hline Term & Definition \\
\hline \multicolumn{2}{|l|}{ Molecular targets } \\
\hline eDNA & $\begin{array}{l}\text { Environmental DNA. Genetic material found in an environmental sample (e.g. air, water, soil). Can include both } \\
\text { extracellular DNA and intracellular DNA, DNA shed from dead or living organisms and sometimes DNA from } \\
\text { whole, microscopic organisms (e.g. mussel veligers). }\end{array}$ \\
\hline eRNA & Environmental RNA. Similar to eDNA, except that RNA is the target molecule. \\
\hline \multicolumn{2}{|l|}{ Sources of eDNA } \\
\hline Relic or legacy & eDNA from non-living sources, for example, from decaying carcasses or as trapped in sediments. \\
\hline Non-local & $\begin{array}{l}\text { eDNA from another location deposited into the local environment by another source, such as a predator or via } \\
\text { sewage contamination. Sometimes referred to as allochthonous eDNA. }\end{array}$ \\
\hline Transient & eDNA deposited by a target species no longer present in the system, as with a migrating individual. \\
\hline Extracellular & $\begin{array}{l}\text { eDNA not encapsulated within a cell, sometimes also referred to as naked, membrane-compromised or free- } \\
\text { floating DNA. Anticipated to degrade faster than intracellular eDNA. }\end{array}$ \\
\hline Intracellular & eDNA within a cell. Anticipated to degrade more slowly than extracellular DNA. \\
\hline mtDNA & $\begin{array}{l}\text { Mitochondrial DNA. Circular DNA found within mitochondria. Common eDNA target, due to supposed high } \\
\text { concentration and long persistence. }\end{array}$ \\
\hline nuDNA & $\begin{array}{l}\text { Nuclear DNA. Linear DNA found within the nucleus of every cell. Less common eDNA target than mtDNA. } \\
\text { Abbreviations used elsewhere include nDNA, ncDNA. }\end{array}$ \\
\hline \multicolumn{2}{|c|}{ Technologies used to amplify eDNA } \\
\hline PCR & $\begin{array}{l}\text { Polymerase Chain Reaction. Method used to amplify DNA in a cyclical pattern, typically involving three steps: } \\
\text { denaturing (separates double-stranded DNA), annealing (PCR primers anchor to the target DNA region, if found } \\
\text { within the sample) and elongation or extension (Taq polymerase synthesises new DNA strands, complementary to } \\
\text { the sequence downstream of annealed primers). Steps are achieved within a thermal cycler, using cyclical heating } \\
\text { and cooling, where amplification is typically allowed to undergo } 25 \text { to } 50 \text { cycle iterations. }\end{array}$ \\
\hline$\overline{\mathrm{CPCR}}$ & $\begin{array}{l}\text { Conventional PCR. Conventional PCR is the oldest and simplest form of PCR. It provides end-point detection, } \\
\text { where successful DNA amplification is observed (as bands in gel electrophoresis) upon completion of the reaction. } \\
\text { For this reason, cPCR is often also referred to as end-point PCR. Amplified products often undergo Sanger } \\
\text { sequencing to confirm the associated DNA sequence matches that of the intended target. }\end{array}$ \\
\hline qPCR & $\begin{array}{l}\text { Quantitative PCR. PCR method that incorporates fluorescent chemistry to achieve real-time, quantitative } \\
\text { detection of amplified DNA. Relative quantification is achieved via comparisons with standard curves. }\end{array}$ \\
\hline $\begin{array}{l}\text { Sanger } \\
\text { sequencing }\end{array}$ & $\begin{array}{l}\text { Method used to read the nucleotide ("sequence") pattern within PCR amplicons (i.e. amplified PCR products). } \\
\text { Often used to verify the identity of positive eDNA samples and to ensure amplified product represents the target } \\
\text { organism. }\end{array}$ \\
\hline HTS & $\begin{array}{l}\text { High-throughput sequencing. Also referred to as next generation sequencing (NGS). Method that allows } \\
\text { for massive, parallel sequencing of numerous DNA fragments (i.e. PCR products). In eDNA applications, } \\
\text { metabarcoding primers are often used to simultaneously generate amplicons for HTS. }\end{array}$ \\
\hline$\overline{\mathrm{ddPCR}}$ & $\begin{array}{l}\text { Droplet digital PCR. Advanced form of qPCR, in which absolute quantification is achieved by partitioning } \\
\text { samples into individual droplets via water-oil emulsion technology. }\end{array}$ \\
\hline CNT/LTS & $\begin{array}{c}\text { Carbon nanotube and light transmission spectroscopy. eDNA amplification and detection methods employing } \\
\text { nanotube materials. }\end{array}$ \\
\hline LAMP & $\begin{array}{l}\text { Loop-mediated isothermal amplification. A method in which DNA is amplified at a single temperature (as opposed } \\
\text { to PCR, which requires cyclical changes in temperature). Requires a unique polymerase (Bst, rather than Taq) and } \\
\text { the use of numerous species-specific primers (typically 6) to create the amplification loop. }\end{array}$ \\
\hline Oligonucleotide & Short, single strand of synthetic DNA/RNA. Commonly used in PCR. \\
\hline Primer & $\begin{array}{c}\text { Oligonucleotide which complements and binds to target DNA/RNA in PCR, initiating amplification of a selected } \\
\text { DNA/RNA fragment. Each PCR reaction requires at least two primers (or a set), typically referred to as the } \\
\text { forward primer and the reverse primer. }\end{array}$ \\
\hline Probe & $\begin{array}{l}\text { Fluorescently-labelled oligonucleotide used in qPCR to increase reaction specificity. Employed simultaneously } \\
\text { with species-specific forward and reverse primers, targeting a third species-specific fragment within the intended } \\
\text { amplicon. Creates the fluorescence in probe-based qPCR applications. }\end{array}$ \\
\hline Assay & $\begin{array}{c}\text { In this publication, we use assay to refer to the primer and probe combination used in probe-based qPCR eDNA } \\
\text { applications. }\end{array}$ \\
\hline $\begin{array}{l}\text { Universal } \\
\text { primers }\end{array}$ & $\begin{array}{l}\text { Synonymous with barcoding primers. A primer set recognised for broad taxonomic coverage, capable of amplifying } \\
\text { DNA from numerous different taxa. Frequently used for species identification purposes, but where DNA is often } \\
\text { amplified from a single organism. Typically combined with Sanger sequencing. }\end{array}$ \\
\hline
\end{tabular}




\begin{tabular}{c|c}
\hline \multicolumn{1}{c|}{ Term } & Definition \\
\hline $\begin{array}{l}\text { Metabarcoding } \\
\text { primers }\end{array}$ & $\begin{array}{c}\text { Similar to universal (barcoding) primers, but specifically optimised for use in HTS amplicon sequencing } \\
\text { ("metabarcoding"). Commonly used to amplify the DNA present in bulk and/or eDNA samples, resulting in } \\
\text { many PCR amplicons representing numerous different taxa. Typically target shorter DNA fragments than universal } \\
\text { (barcoding) primers. }\end{array}$ \\
\hline Metabarcoding & $\begin{array}{c}\text { An HTS application. The (simultaneous) sequencing of a PCR product containing a mix of amplified DNA } \\
\text { fragments ("amplicons"), where the amplicons are generated using metabarcoding primers and represent the DNA } \\
\text { of targeted organisms found within bulk and/or eDNA samples. Subsequent bioinformatic analyses are required to } \\
\text { assess species composition. }\end{array}$ \\
\hline
\end{tabular}

\section{Terms relevant to method validation}

\begin{tabular}{|c|c|}
\hline $\begin{array}{l}\text { Mock } \\
\text { community }\end{array}$ & $\begin{array}{l}\text { An experimental sample in which the sample contains a mixture of target DNA templates at known concentrations } \\
\text { and/or of a known composition. Sample is created to mimic the species composition present in environmental } \\
\text { samples. Often used to evaluate the sensitivity and specificity of HTS metabarcoding primer pairs. }\end{array}$ \\
\hline Spiked sample & $\begin{array}{l}\text { An experimental sample in which target DNA (either tissue-derived or, more often, synthetic) is added at a known } \\
\text { concentration. Spiked samples can be used at different stages of the eDNA workflow and are often employed to test } \\
\text { the reliability of eDNA methods. }\end{array}$ \\
\hline $\begin{array}{l}\text { Quality } \\
\text { Assurance- } \\
\text { Quality Control } \\
\text { (QA-QC) }\end{array}$ & $\begin{array}{l}\text { A set of protocols, measures and guidelines to ensure quality eDNA results (including, reproducibility and } \\
\text { repeatability). Please reference Goldberg et al. (2016) for a detailed list specific to eDNA surveys. }\end{array}$ \\
\hline In silico & $\begin{array}{l}\text { Method used to assess the specificity of eDNA primers and/or assays. Typically represents the first validation step, } \\
\text { where primer/assay sequences for the target species are compared to sequences of non-target (and often related and/ } \\
\text { or co-occurring) species using data available from DNA repositories (e.g. NCBI's Genbank). }\end{array}$ \\
\hline In vitro & $\begin{array}{l}\text { Method used to assess the specificity and sensitivity of eDNA primers and/or assays. Typically represents the } \\
\text { second validation step, where PCR amplification is attempted for target and non-target species using primers/assays } \\
\text { determined to be species-specific during in silico testing. DNA used in the PCR is often invasively collected (i.e. } \\
\text { extracted from tissues). }\end{array}$ \\
\hline In situ & $\begin{array}{l}\text { Method used to assess the specificity and sensitivity of eDNA primers and/or assays. Typically represents the third } \\
\text { (and final) validation step, where species-specific primers/assays passing in silico and in vitro testing are employed } \\
\text { using eDNA samples collected from sites where the target species is known to occur and where the target species is } \\
\text { known to be absent. Ensures that the assays work as intended, with positive detections in occupied sites and with } \\
\text { no detections (i.e. false positives) in unoccupied sites. Success indicates that the primers/assays are ready for field } \\
\text { application, where target species presence/absence is unknown. }\end{array}$ \\
\hline $\begin{array}{l}\text { Limits of } \\
\text { detection }\end{array}$ & $\begin{array}{l}\text { Abbreviated LOD. A measure of sensitivity. Required to reliably distinguish detections from non-detections in } \\
\text { qPCR and ddPCR applications. LOD represents the lowest eDNA concentration at which } 95 \% \text { of technical } \\
\text { replicates amplify (i.e. are detected), as based on a serial dilution of target DNA. False negative detections may } \\
\text { occur at concentrations below the LOD. For relevant guidelines/discussions, see Bustin et al. (2009) and Klymus } \\
\text { et al. (2020b). }\end{array}$ \\
\hline $\begin{array}{l}\text { Limits of } \\
\text { quantification }\end{array}$ & $\begin{array}{l}\text { Abbreviated LOQ. Determines precision of quantification (i.e. ability to quantify eDNA copy number). Lowest } \\
\text { eDNA concentration at which samples can be reliably quantified using qPCR or ddPCR. Based on a serial dilution } \\
\text { of target DNA, where the coefficient of variation is below } 35 \% \text {. Concentrations below the determined LOQ } \\
\text { cannot be reliably quantified. For relevant guidelines/discussion, see Klymus et al. (2020b). }\end{array}$ \\
\hline
\end{tabular}

Challenges encountered

\begin{tabular}{l|c}
\hline PCR inhibition & $\begin{array}{c}\text { Reduction of DNA amplification efficiency during PCR due to presence of substances co-extracted from } \\
\text { environmental samples (e.g. humic acids). PCR inhibition can contribute to imperfect detection and inaccurate } \\
\text { quantification. }\end{array}$ \\
\hline False negatives & $\begin{array}{r}\text { Failure to detect eDNA of the target organism, even when the target organism is present in the sampled } \\
\text { environment. Can be a result of, amongst other factors, eDNA methods exhibiting low sensitivity, inappropriately } \\
\text { designed primers that fail to amplify DNA of target taxon, low tolerance to PCR inhibitors and/or poor sampling } \\
\text { protocols (design, timing, replication). }\end{array}$ \\
\hline False positives & $\begin{array}{c}\text { Erroneous detection of the target organism when the target organism is absent from the sampled environment. } \\
\text { Can be caused by amplification of non-target organisms (poor specificity of the assay) or by cross-contamination } \\
\text { (poor QA-QC, lab and field protocols). For important nuances regarding the term "false positive", see Darling et } \\
\text { al. (2021). }\end{array}$ \\
\hline $\begin{array}{l}\text { PCR primer/ } \\
\text { amplification } \\
\text { bias }\end{array}$ & $\begin{array}{c}\text { Preferential amplification of DNA from more abundant species or of species whose DNA contains fewer } \\
\text { mismatches to the primer sequence. Causes variation of amplification efficiency amongst taxa. PCR primer bias is } \\
\text { especially problematic in HTS when using metabarcoding primers and leads to losses in detection sensitivity (i.e. } \\
\text { false-negative results) for some species and/or the inability to quantitatively assess eDNA results. }\end{array}$ \\
\hline
\end{tabular}




\begin{tabular}{l|c}
\hline \multicolumn{1}{c|}{ Term } & Definition \\
\hline $\begin{array}{l}\text { Tag hopping } \\
\text { or swapping }\end{array}$ & $\begin{array}{c}\text { HTS sequencing issue in which sequence reads are mis-assigned to samples. In the HTS workflow, individual } \\
\text { samples (within a pooled sample) are identified by unique identifiers, called a tag or index, composed of short } \\
\text { nucleotide fragments which are appended to the ends of PCR products during library preparation; sometimes, } \\
\text { these unique identifiers get mismatched during preparation and/or during sequencing in a process called tag- or } \\
\text { index-hopping. As a result, sequence reads are matched to the wrong sample, confounding results and potentially } \\
\text { increasing the risk of false-positive detections. May be minimised by applying unique pairs of indexes ("dual } \\
\text { indexes"; one index for each end of template DNA) instead of only a single unique index for each sample. }\end{array}$ \\
\hline $\begin{array}{c}\text { eDNA is subject to biotic and abiotic factors which contribute to its degradation. Decay refers to the reduction } \\
\text { in detectable quantities of eDNA over time as a result of degradation. The rate of decay can impact eDNA survey } \\
\text { success and must be considered for interpretations beyond presence/absence. }\end{array}$ \\
\hline
\end{tabular}

(hereafter, cPCR) techniques were used to discriminate juvenile specimens of both species which had been tentatively sorted, based on morphology (Claxton et al. 1997). Here, efforts relied on the commonly used mitochondrial DNA (mtDNA) barcode locus, cytochrome c oxidase subunit $I(C O I)$, using universal primers recognised for their broad taxonomic coverage (Folmer et al. 1994; Hebert et al. 2003). Subsequent work incorporated the design and testing of newly-developed, species-specific primer sets, unique to QM or ZM. These species-specific primers targeted a variety of QM-ZM genes (mitochondrial COI and 16S rRNA genes and a nuclear gene for 18S rRNA) and were used as diagnostic markers to discriminate amongst microscopic, larval veligers collected via plankton tows. The DNA analysed in all methods was acquired from whole QM-ZM veligers. Early methods required an initial step to pre-sort and individually isolate veligers found within the plankton tows (Claxton and Boulding 1998). Later methods skipped this step and utilised bulk, unsorted tow samples (Frischer et al. 2002; Ram et al. 2011).

These foundational studies provided the knowledge and methodology necessary for expedited, molecular-based dreissenid identification at all life stages, thereby circumventing the need for rare taxonomic expertise. Furthermore, PCR-based approaches were proving to be far more sensitive than more traditional techniques. For example, Frischer et al. (2002) developed a cPCR method (targeting a nuclear gene for $18 \mathrm{~S} \mathrm{rRNA}$ ) that specifically identified and detected microscopic ZM veligers in bulk samples containing diverse and unsorted arrays of whole planktonic species. Not only was this cPCR-based method able to discriminate amongst numerous taxa (including other invasive bivalves, for example, QM and Asian freshwater clam, Corbicula fluminea), its detection ability was estimated to be "300 times more sensitive than cross-polarized light microscopy" (Frischer et al. 2002). Yet a decade later, Frischer et al. (2012) observed poor sensitivity using the same cPCR-based methods, where veligers often went undetected. Observations in Frischer et al. (2012) and Hosler et al. (2017) revealed that detection results, based on PCR, can be significantly impacted by expertise in molecular techniques, including familiarity with appropriate sample/DNA preservation methods. Nevertheless, these early findings, based on whole specimens, paved the way for more complex QM-ZM surveillance endeavours utilising eDNA sampling. 


\section{Early eDNA-like studies}

Moving beyond whole specimens and bulk samples, Carmon et al. (2014) demonstrated the successful detection of lab-manipulated, free-floating QM eDNA within water samples, culminating several years worth of research conducted by the same lab (e.g. see Keele et al. 2013 and protocols/references therein). Here, the authors used COI primers developed by Keele et al. (2013) and combined cPCR with first generation (i.e. Sanger) sequencing to confirm specificity of amplified PCR products. These early eDNA primers and others (e.g. Frischer et al. 2002), target relatively long DNA fragments (often $>>300 \mathrm{bp}$ ). Optimised guidance now suggests eDNA primers should target DNA fragments < 250 bp (e.g. Klymus et al. 2020a), as smaller fragments are more likely to be detected in highly degraded and/or eDNA samples (Thomsen and Willerslev 2015). Still, in this experimental study, eDNA-based detection was more sensitive than traditional detection methods (specifically, light microscopy), especially when veligers had undergone structural degradation (i.e. undergone a bead-beating process or exposure to an acidic solution) prior to eDNA sampling and PCR. Yet, the authors noted a high prevalence of false negatives in their experimental eDNA samples (Carmon et al. 2014), where mussels were known to be present, but their DNA not detected. These findings indicated that additional optimisations were needed for QM$\mathrm{ZM}$ eDNA sampling, processing and analyses to achieve greater detection success.

\section{Conventional PCR}

Moving out of the lab and into infested waters, Lance and Carr (2012) coupled cPCR (targeting 18S; Frischer et al. 2002) and confirmatory Sanger sequencing with a propidium monoazide (PMA) pre-treatment. Propidium monoazide is a photoreactive dye that binds to DNA and subsequently inhibits PCR, but is incapable of permeating cell membranes (Nocker et al. 2007; Bae and Wuertz 2009). Since PMA cannot infiltrate intact cells, it was predicted that PMA could assist in the targeted detection of DNA from whole veligers, as opposed to (extracellular, free-floating) eDNA shed from adult mussels. The results of this pilot study were positive in that capture and detection of ZM eDNA was successfully demonstrated using water samples collected from a known-infested, natural setting. However, PMA's ability to discriminate between whole veligers and extracellular eDNA was not confirmed (i.e. PMA results were inconsistent with expectations). The appeal of PMA has since waned. Evidence now suggests that eDNA shed from live organisms can contain a mixture of both membrane-bound DNA (i.e. intracellular) and extracellular DNA (Turner et al. 2014), making PMA treatment ineffectual for veliger-specific detection.

\section{Nanoparticle technologies: Carbon nanotube and light transmission spectroscopy}

Most eDNA technologies require some form of PCR. This is because PCR is effective in amplifying minute amounts of DNA such that it can be readily detected in 
downstream analyses. However, some early eDNA studies aimed to eliminate reliance on PCR and thus improve rapid, on-site (in situ) QM-ZM surveillance in ballast and/ or harbour waters. These efforts focused on the application of novel DNA hybridisation methods and employed nanoparticle materials, using one of two relevant technologies, either microfluidic carbon nanotube chips (CNT, Mahon et al. 2011) or light transmission spectroscopy (LTS, Li et al. 2011; Egan et al. 2013, 2015; Mahon et al. 2013). Despite goals to be PCR-free, all publications incorporated cPCR as an initial step in QM-ZM eDNA detection, with most utilising universal invertebrate primers (Folmer et al. 1994) for amplification purposes. Detection of QM-ZM was met with mixed success. For example, in the most recent LTS publication, Egan et al. (2015) sampled waters known to be infested by both species, but could only detect QM. Follow-up publications, demonstrating improved detection and/or PCR-free CNT/ LTS advancements, have not emerged. A likely explanation is that costs associated with nanoparticle technologies are prohibitive to further development and widespread application. Or, perhaps PCR-free CNT/LTS endeavours failed to produce reliable QM-ZM detection results. Subsequently, CNT/LTS eDNA technologies have not been widely adopted. An alternative PCR-free strategy has more recently emerged for QM-ZM eDNA surveys and is described in a sub-section below, where loop-mediated isothermal amplification is detailed.

\section{Quantitative PCR}

In contrast to the endpoint analyses of cPCR (Fig. 2), quantitative PCR (qPCR) employs fluorescent chemistry that produce DNA amplification curves which can be visualised or monitored throughout the reaction (Wittwer et al. 1997). With qPCR, there are two basic chemistry options: dye-based (e.g. SYBR Green) and probe-based (e.g. TaqMan; Heid et al. 1996). Fluorescence is achieved differently with each. Fig. 2 illustrates these basic differences, but for a more thorough review and relevant background information, see Arya et al. (2005). It is important to note that probe-based qPCR is often preferred for eDNA applications (Herder et al. 2014), as it achieves greater specificity through the use of a target-specific, fluorescently-labelled third oligonucleotide ("probe"), as opposed to dye-based qPCR which utilises a fluorescent chemistry that non-specifically binds to any double-stranded DNA present in the reaction, potentially producing false positive detections, if DNA from non-target organisms is amplified (Marmiroli and Maestri 2007).

In qPCR, fluorescence increases over the duration of the reaction and is reflective of the amount of DNA amplified at each cycle (Higuchi et al. 1992, 1993). Thus, qPCR amplification curves can be used to indirectly quantify the original amount (or starting concentration) of target-DNA present in an eDNA sample using comparisons with a standard curve (Takahara et al. 2012). These standard curves are generated from serially-diluted, known-concentration (and often synthetic; Conte et al. 2018) DNA templates (Fig. 2). One advantage of qPCR, then, compared to cPCR, is that it not only provides a mechanism for inferring the presence/absence of target taxa, it also provides the potential for estimating taxa abundance (i.e. relative density or biomass, 


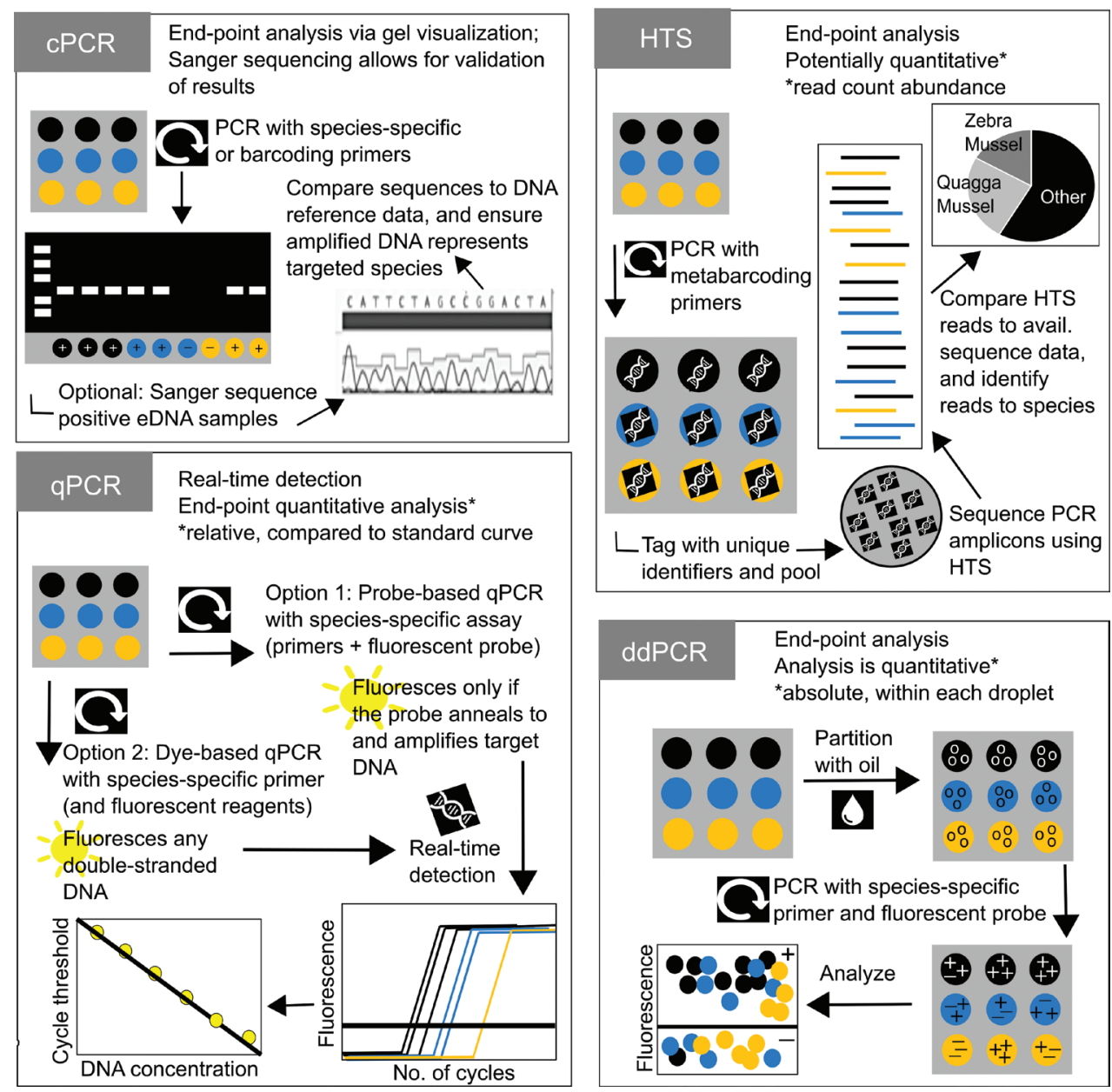

Figure 2. Detailed descriptions of common and emerging quagga mussel and zebra mussel (QM-ZM) environmental DNA (eDNA) amplification strategies. Quantitative PCR (qPCR) and high-throughput sequencing (HTS) represent the most commonly used technologies in quagga and zebra mussel eDNA studies. Droplet digital PCR (ddPCR), an advanced form of qPCR, is an emerging technique with popularity likely to increase due to its high tolerance of PCR inhibitors, improved quantification and observed sensitivity. Here, we detail the specifics of each technique, highlighting how detection and quantification occurs with each. Colours represent three hypothetical environmental DNA (eDNA) samples, at three technical (i.e. lab, amplification) replicates. Positive symbols represent eDNA detection. Negative symbols represent no eDNA detection. Conventional PCR (cPCR) is a foundational technology which gave rise to the other amplification strategies. It is no longer a common eDNA approach (due to low sensitivity), but we include it here for comparative purposes.

but not absolute numbers). Correlations between these metrics and estimated concentrations of eDNA have been found (e.g. Thomsen et al. 2012; Pilliod et al. 2013), even in QM-ZM (Peñarrubia et al. 2016; De Ventura et al. 2017; Marshall et al. 2021). Caution is advised, however, as eDNA concentration may not scale predictably with 
biomass (Mauvisseau et al. 2019; Shogren et al. 2019; Sepulveda et al. 2020a). For a review and meta-analysis of this issue, see Yates et al. (2019), where it is suggested that further refinement is needed for reliable eDNA-based estimations of abundance.

In an early attempt to develop qPCR markers for ZM, Tucker (2014) designed a probe-based $C O I$ assay and tested it for specificity against non-target QM and Asian clams (Corbicula fluminea, hereafter, Corbicula). In trials utilising cPCR, dye-based qPCR and probe-based qPCR, the author found the assay was not ZM-specific, but instead amplified both QM and ZM. Furthermore, detection success was noted to be inconsistent in lab-simulated, eDNA-like samples (reservoir water "seeded" with ZM veligers before DNA extraction). The author concluded that, in future studies, optimisation of eDNA extraction techniques was needed and emphasised the importance of developing species-specific primers to achieve QM-ZM management goals.

Moving into field-based qPCR detection, Bollens et al. (2015) designed two multiplexed, species-specific, probe-based qPCR assays for QM and ZM. A multiplexed reaction employs multiple assays in a single PCR and, with appropriate optimisation, enables the detection of either multiple species (by incorporating several species-specific assays) and/or multiple different loci targeting one species of interest (by incorporating several assays targeting different genes); the latter has been shown to increase eDNA detection success (e.g. Lance and Guan 2019). Both assays developed by Bollens et al. (2015) targeted the cytochrome B (CytB) locus of the mitogenome, but with one assay specific to $\mathrm{ZM}$ and the other specific to $\mathrm{QM}$. These assays were intended for use in the Columbia River Basin (CRB), US, which has yet to be invaded by either Dreissena, but represents a highly-susceptible, regularly-monitored watershed. Interestingly, an additional eDNA assay for Corbicula (known to be established in the River Basin) was simultaneously developed and employed by the authors as a methodological positive control, thereby establishing the effective deployment of all phases of the eDNA survey. Experimental evaluation indicated that the Corbicula assay could not be run in multiplex with the QM-ZM assays, as this resulted in a loss of detection sensitivity for ZM. The Corbicula assay was, thereafter, run separately from the dreissenid assays. Asian clams were consistently detected across all sampled sites during the eDNA survey effort, but neither QM or ZM were detected.

To the best of our knowledge, the Bollens et al. (2015) CytB assays have yet to be tested in waters known to have QM or ZM infestations. The reason for this is unclear. Perhaps it is because details regarding assay specificity are missing, with no information provided as to how the assays were evaluated for amplification in potentially cooccurring, non-target species (e.g. in silico, in vitro). In contrast, greater emphasis was placed on QM-ZM specificity during the development of later-occurring probe-based QM-ZM qPCR assays (e.g. Amberg and Merkes 2016; Gingera et al. 2017; Sepulveda et al. 2019), garnering these more recent - and demonstrably more specific - assays greater popularity for deployment in recent surveys. The incorporation of probe-based qPCR chemistry and thorough testing for specificity are known to increase targetspecies detection precision, including reducing the risk of false positives and, thus, improve the reliability of eDNA results (e.g. Wilcox et al. 2013). 
Meanwhile, some authors were employing dye-based qPCR methods. Peñarrubia et al. (2016) published a dye-based qPCR method targeting the nuclear, single-copy histone $H 2 B$ gene in QM-ZM (Table 3). The method proved successful for indiscriminate detection of both mussels in Spanish lentic systems, with observed greater detection sensitivity than a simultaneously employed, traditional microscopy-based survey method. Furthermore, Peñarrubia et al. (2016) implemented a pre- and postspawning season sampling scheme which, when combined with the quantitative abilities afforded by qPCR, provided novel findings for the seasonal- and life-stage-specific dynamics of dreissenid eDNA. Specifically, results from their study indicated greater amounts of QM-ZM eDNA were present in the autumn season, which they attributed to increased veliger presence following successful summer spawning. The authors drew two important conclusions, both of which would influence the approaches and interpretations of later occurring surveys: 1) qPCR could be used to estimate levels of QM-ZM infestation via quantification of Dressenid eDNA and 2) QM-ZM eDNA sampling could be optimised by capitalising on spawning activity, where mass veliger concentrations provide ample sources of DNA.

Continuing with efforts to refine sampling protocols, Amberg and Merkes (2016) and Amberg et al. (2019) provided a comparison of multiple different strategies, including methods that employed sampling from different levels of the water column (surface, mid-water and near the bottom), sampling from waters overlaying either hard or soft substrates (where mussels may or may not settle, respectively) and sampling at two seasonal intervals. Samples were collected from across two different lakes, one where ZM was densely established and another where ZM was newly invaded. Relationships between eDNA and environmental covariates (i.e. depth and substrate) differed between the two lakes. Generally, though, findings indicated that the concentration of ZM eDNA increased with depth and decreased at suspected habitat (i.e. hard substrates). To explain this observation, the authors hypothesised that ZM eDNA drifts to and settles at deeper sections of the lake, where it is less susceptible to degradation and where softer sediments coincidentally exist. It should be noted that, while QM-ZM are filter feeders, their filtering activity does not appear to increase local eDNA degradation rates (Mächler et al. 2018).

The probe-based assay developed and used in Amberg and Merkes (2016; Amberg et al. 2019), was - according to the authors - the first of its kind to be validated for specificity to ZM. The assay, DRE2 (Table 3) combines a dreissenid-specific COI primer set with a ZM-specific probe. It has recognised utility throughout the Great Lakes Region, having been screened for specificity against 27 non-target fish and mussel species common to the area. It has been subsequently employed in a number of publications (e.g. Sepulveda et al. 2019, 2020a; Shogren et al. 2019), but with evidence to suggest it has relatively low sensitivity (potentially due to its low annealing temperature) and, thus, presents a risk for false negative results (Sepulveda et al. 2019, 2020a).

Three alternative - and high-performing (Sepulveda et al. 2020a) - probe-based assays developed by Gingera et al. (2017) have become some of the most prevalently used qPCR assays in North American QM-ZM eDNA surveillance efforts (e.g. Devlin 
Table 3. Metabarcodes and assays proven effective for environmental DNA/RNA surveillance of quagga (D. rostriformis bugensis, QM) and zebra (D. polymorpha, ZM) mussels, narrowed to those employed and/ or developed in the last five years (since 2016).

\begin{tabular}{|c|c|c|}
\hline Primer & Targets & Sequence $\left(5^{\prime}\right.$ to 3 ') \\
\hline \multirow{2}{*}{\multicolumn{3}{|c|}{$\begin{array}{l}\text { HTS metabarcodes } \\
\text { (ordered by increasing specificity) }\end{array}$}} \\
\hline & & \\
\hline \multicolumn{3}{|c|}{ Blackman et al. (2020a); Mychek-Londer et al. (2020) (originally developed by Geller et al. 2013; Leray et al. 2013) } \\
\hline \multirow{2}{*}{$\begin{array}{l}\text { mICOIintF, } \\
\text { jgHCO2198 }\end{array}$} & Metazoans & F: GGWACWGGWTGAACWGTWTAYCCYCC \\
\hline & COI & R: TAIACYTCIGGRTGICCRAARAAYCA \\
\hline \multicolumn{3}{|c|}{ Ardura et al. (2017) (originally developed by Geller et al. 2013) } \\
\hline \multirow{2}{*}{$\begin{array}{l}\text { jgLCO1490, } \\
\text { jgHCO2198 }\end{array}$} & Marine Invertebrates & F: TITCIACIAAYCAYAARGAYATTGG \\
\hline & COI & R: TAIACYTCIGGRTGICCRAARAAYCA \\
\hline \multicolumn{3}{|c|}{ Brown et al. (2016) (originally developed by Zhan et al. 2013) } \\
\hline \multirow[t]{2}{*}{ Uni18S } & Crustaceans, Molluscs, Tunicates & F: AGGGCAAKYCTGGTGCCAGC \\
\hline & $18 \mathrm{~S}$ & R: GRCGGTATCTRATCGYCTT \\
\hline \multicolumn{3}{|c|}{ Klymus et al. (2017) } \\
\hline \multirow[t]{2}{*}{ MOL16S } & Molluscs & F: RRWRGACRAGAAGACCCT \\
\hline & $16 S$ & R: ARTCCAACATCGAGGT \\
\hline \multicolumn{3}{|c|}{ Prié et al. (2020) } \\
\hline \multirow[t]{2}{*}{ Vene01 } & Bivalves & F: CSCTGTTATCCCYRCGGTA \\
\hline & $16 S$ & R: TTDTAAAAGCCGAGAAGACCC \\
\hline \multicolumn{3}{|c|}{ Marshall and Stepien (2019) } \\
\hline \multirow[t]{2}{*}{ COIA } & QM-ZM & F: AGTGTTYTKATTCGTTTRGAGCTWAGKGC \\
\hline & COI & R: GAYAGGTARAACCCAAAAWCTWAC \\
\hline \multicolumn{3}{|c|}{ DYE-BASED qPCR primers } \\
\hline \multicolumn{3}{|c|}{ Peńarrubia et al. (2016) } \\
\hline \multirow[t]{2}{*}{$\mathrm{H} 2 \mathrm{~B}$} & QM-ZM & F: CGCGCGCTCCACTGACAAGA \\
\hline & $\mathrm{H} 2 \mathrm{~B}$ & R: CACCAGGCAGCAGGAGACGC \\
\hline \multicolumn{3}{|c|}{ De Ventura et al. (2017) (originally developed by Bronnenhuber and Wilson 2013) } \\
\hline \multirow[t]{2}{*}{ DbuCOI3 } & QM & F: GGGGTTGAACATTATAYCCACCGTT \\
\hline & COI & R: AAACTGATGACACCCGGCACG \\
\hline \multirow[t]{2}{*}{ DpoCOI3 } & $\mathrm{ZM}$ & F: GCTAAGGGCACCTGGAAGCGT \\
\hline & COI & R: CACCCCCGAATCCTCCTTCCCT \\
\hline \multicolumn{3}{|c|}{ Blackman et al. (2020a) (originally developed by Blackman et al. 2020b) } \\
\hline \multirow[t]{2}{*}{ DRB1 } & QM & F: GGAAACTGGTTGGTCCCGAT \\
\hline & COI & R: GGCCCTGAATGCCCCATAAT \\
\hline \multicolumn{3}{|c|}{ Marshall et al. (2021) } \\
\hline \multirow[t]{4}{*}{$16 S$} & QM-ZM & F1: GTTAATAGCTGTGCTAAGGTAGC (long amplicon) \\
\hline & $16 S$ & F2: TGGGGCAGTAAGAAGAAAAAAATAA* (short amplicon) \\
\hline & mtDNA, mt-rRNA & R: CATCGAGGTCGCAAACCG* \\
\hline & & ${ }^{*}$ Gingera et al. (2017) \\
\hline \multirow[t]{3}{*}{ COI } & QM-ZM & F: ATTTTATCTCTTCATATYGGGGGAGC \\
\hline & COI & R: CCAATAGAWGTRCARAACAAAGG \\
\hline & mtDNA, mt-mRNA & \\
\hline $18 \mathrm{~S}$ & QM-ZM & F: AACYCGTGGTGACTCTGGAC** \\
\hline & $18 \mathrm{~S}$ & R: GTGTCTCATGCTCCСTCTCC* \\
\hline & nuDNA, nu-rRNA & *modified from Williams et al. (2017) \\
\hline $\mathrm{H} 2 \mathrm{~B}$ & QM-ZM & F1: CGCGCGCTCCACTGACAAGA* (long amplicon) \\
\hline & $\mathrm{H} 2 \mathrm{~B}$ & F2: TTGCCCACTACAACAAGCGA (short amplicon) \\
\hline & nuDNA, nu-mRNA & R: CACCAGGCAGCAGGAGACGC* \\
\hline & & *Peńarrubia et al. (2016) \\
\hline
\end{tabular}




\begin{tabular}{|c|c|c|}
\hline Primer & Targets & Sequence (5' to 3 ') \\
\hline \multicolumn{3}{|c|}{ Gingera et al. (2017) } \\
\hline \multirow[t]{5}{*}{ DRE16S } & QM-ZM & F: TGGGGCAGTAAGAAGAAAAAAATAA \\
\hline & $16 S$ & Probe: CCGTAGGGATAACAGC \\
\hline & & Alt. Probe*: AAAGTTACCGTAGGGATAACAGCGTTATCG \\
\hline & & R: CATCGAGGTCGCAAACCG \\
\hline & & *developed by Devlin and Youngbull (2019) \\
\hline \multirow[t]{3}{*}{ ZEBCOI } & $\mathrm{ZM}$ & F: SCCTGCGATAGATTTTTTGATTTTA \\
\hline & COI & Probe: CGTGCTGGATGTCAT \\
\hline & & R: GCAGAACAAAGGGACCCG \\
\hline \multirow[t]{3}{*}{ ZEBCYT } & $\mathrm{ZM}$ & F: CATTTTCTTATACCTTTTATTTTATTAGTGCTTTT \\
\hline & CytB & Probe: TAGGTTTTCTTCATACTACTGGC \\
\hline & & R: CGGGACAGTTTGAGTAGAAGTATCA \\
\hline \multicolumn{3}{|c|}{ Amberg et al. (2019) } \\
\hline \multirow[t]{3}{*}{ DRE2 } & $\mathrm{ZM}$ & F: TGGGCACGGGTTTTAGTGTT \\
\hline & $\mathrm{COI}$ & Probe: CGTCCTTGGTG \\
\hline & & R: CAAGCCCATGAGTGGTGACA \\
\hline \multicolumn{3}{|c|}{ Sepulveda et al. (2019) } \\
\hline \multirow[t]{3}{*}{ DREQM } & QM & F: CTCTTCATATCGGTGGAGCTTC \\
\hline & $\mathrm{COI}$ & Probe: CCCGGCACGTATATTTCCTCATGTT \\
\hline & & R: CAAAGGCACCCGATAAAACTG \\
\hline \multicolumn{3}{|c|}{ LAMP primers } \\
\hline \multicolumn{3}{|c|}{ Williams et al. (2017) } \\
\hline QM-ZM & FIP: TGA & CGGCGAACTCGTGGTGACTCTGGAC \\
\hline \multirow[t]{5}{*}{$18 \mathrm{~S}$} & BIP: TGC & TAACGGGTGTCTCATGCTCCCTCTCC \\
\hline & & GATCGGCACAAAGTT \\
\hline & & GGGAATCAGGGTTCG \\
\hline & & GCCCAGACCAACGC \\
\hline & & TTGGATGTGGTAGCC \\
\hline $\mathrm{ZM}$ & FIP: AGAGACA & AAACTAATTGATTGGTACCAATAATACTGAG \\
\hline \multirow[t]{5}{*}{$\mathrm{COI}$} & BIP: ATTT' & AGGGAAGGAAAAATCTATCGCAGGGCC \\
\hline & & AAACCTATATCAGGAAGA \\
\hline & & GGGGGGTGGTTGAACC \\
\hline & & GGGGGGATTCGGAA \\
\hline & & CCCCAATATGAAGAG \\
\hline QM & FIP: AAGA & ГATGAAGAGCCACCGTTATCCAGGATT \\
\hline \multirow[t]{5}{*}{ COI } & BIP: AGAACA & GTGCCCACCAATAGAAGTACAAAACAAAG \\
\hline & & CTGGCCCTGAATGCC \\
\hline & & CATCAGTTTTATCGGGT \\
\hline & & GGTGGGGGTTGAAC \\
\hline & & AAACAGGTATTGCTAA \\
\hline
\end{tabular}

and Youngbull 2019; Sepulveda et al. 2019, 2020a; Trebitz et al. 2019; Watts 2020; Marshall et al. 2021). These assays are commonly cited in literature as ZEBCOI, ZEBCYT and DRE16S (Table 3), with ZEBCOI and ZEBCYT being specific to ZM and DRE16S generically targeting both QM and ZM. During development, all assays underwent thorough vetting for specificity to QM-ZM, with particular emphasis in the Great Lakes Region of North America, via trials with 10 native, non-target mussels. When originally deployed, Gingera et al. (2017) used these novel assays along an invasion front, where qPCR-based eDNA surveys were used for early detection purposes. Results provided positive eDNA detections (later confirmed via visual surveys) in high- 
risk areas, where QM-ZM had either been previously eradicated and possibly recolonised or not yet documented. The authors employed a seasonal sampling scheme and, in agreement with Peñarrubia et al. (2016), also observed increased detection success during autumn months. A number of possible explanations were provided to account for lower detection success during the spring months, including increased dilution due to snow-melt and potential cold-season (winter) die-off. Support for the hypothesis that dilution plays a significant role in the success of QM-ZM eDNA surveys was later demonstrated by Trebitz et al. (2019). Akin to Peñarrubia et al. (2016), the increased detection success, observed by Gingera et al. (2017) in autumn, was attributed to QMZM life history, where whole-veliger presence, post-spring/summer spawning, likely contributes to ease of eDNA detection.

De Ventura et al. (2017) discussed how veliger presence in eDNA samples may impact the performance of different technologies and the ability to accurately quantify eDNA. The study compared the performance of cPCR and dye-based qPCR, employing two species-specific $\mathrm{CO} I$ assays (DbuCOI3 and DpoCOI3; Table 3 ) developed by Bronnenhuber and Wilson (2013). Both eDNA methods appeared to outperform conventional survey techniques (i.e. kick-net sampling and scuba surveys), with similar levels of detection achieved in waters from previously invaded reaches and in waters at the edge of an invasion front. However, the authors concluded that cPCR was a more robust method and could potentially outperform qPCR by being less prone to false positives (due to cPCR possessing lower sensitivity than $\mathrm{qPCR}$ ). Even so, the authors were able to demonstrate the utility and advantage of using qPCR. Here, De Ventura et al. (2017) found that eDNA concentrations (estimated via qPCR) were positively correlated with known mussel densities, indicating that QM-ZM eDNA concentrations can be linked to population densities via biomass (at least in some cases). The authors, however, recommended mesocosm experimentation to further investigate this relationship, stating that the concentration and quantification of eDNA may be influenced by several factors, including veliger presence, PCR inhibitors and environmental conditions.

As De Ventura et al. (2017) eluded, eDNA is subject to environmental factors that impact its transport, persistence and degradation (for reviews, please see Barnes and Turner 2016; Harrison et al. 2019). To better understand how these factors influence ZM eDNA surveys in lotic waters, as well as how they influence the interpretation of eDNA concentrations for biomass, Shogren et al. (2019) conducted an eDNA survey along a 7-km stretch of an infested river in Denmark during the nonreproductive season. Using DRE2 (Amberg and Merkes 2016; Table 3), the authors investigated the relationship between eDNA concentration and ZM density, while considering site characteristics (river physicochemical and hydrologic variables, including velocity, macrophyte cover, temperature, $\mathrm{pH}$, substrate type, chlorophyll a and nutrients) and mussel eDNA shed and decay rates (Sansom and Sassoubre 2017). Results revealed complex relationships amongst variables, highlighting the difficulty in accurately estimating mussel biomass/abundance solely from eDNA quantitative 
data. Specifically, Shogren et al. (2019) found a weak relationship between ZM density and eDNA concentration. A stronger relationship was observed between water velocity, nutrient concentration and the spatial distribution of $\mathrm{ZM}$ eDNA. The authors suggested these findings could be used to develop future sampling strategies, where the fate of eDNA may be best predicted using hydrological modelling (e.g. eDNA transportation models, such as in Carraro et al. 2018 and as more recently detailed in Carraro et al. 2020).

Using multi-scale occupancy modelling, Sepulveda et al. (2019) investigated how sampling strategies (specifically, intensity and timing) may impact eDNA detection success in North American QM-ZM surveys. Here, the authors used three assays: a newly-developed QM-specific COI assay (designated DREQM and tested against 15 non-target taxa; Table 3), DRE16S (Gingera et al. 2017) and DRE2 (Amberg et al. 2019). Results indicated that, amongst filtered samples collected in June, July and October, the greatest sampling-to-detection efficiency was observed in July, when the reproductive season appeared to afford a higher probability of detection. Yet, the authors reiterated previous recommendations that sample replication plays a crucial role in the probability of detection and overall eDNA survey success (e.g. Ficetola et al. 2015; Furlan et al. 2016; Willoughby et al. 2016). With QM-ZM, a fairly large number of eDNA field samples were needed to achieve high levels of detection confidence, with $\geq 27$ and 14 samples required, respectively, for June/October and July eDNA survey endeavours.

By 2020, it was clear that field-based methodological approaches (e.g. seasonal timing, replication etc.) impacted the outcomes of QM-ZM eDNA surveys. Yet, no study had compared the outcomes, based on assay choice. To remedy this issue, Sepulveda et al. (2020a) published a "double-blind, round-robin validation" for five of the most commonly used QM-ZM-specific, probe-based qPCR assays (DRE16S, ZEBCOI, ZEBCYT from Gingera et al. 2017; DRE2 from Amberg et al. 2019; DREQM from Sepulveda et al. 2019). In this study, filtered waters were collected from seven widely disjunct lotic and lentic locales in the US where QM-ZM infestations were either known or unknown. Samples were analysed across several labs and outcomes compared. Results were highly reproducible (i.e. consistent and, thus, reliable) across labs and largely across assays, with the following caveat: DRE16S outperformed all other assays, while DRE2 performed the least effectively (as previously mentioned, likely due to unusually low annealing temperatures). Although the authors acknowledged that using multiple assays could reduce the occurrence of false negative results (and, logically, improve overall survey power and accuracy), they cautioned against multiplexing the tested assays, citing findings from Gingera et al. (2017), which suggested that multiplexing decreased associated assay performance. Furthermore, Sepulveda et al. (2020a) noted imprecise and inaccurate eDNA quantification in spiked water samples (i.e. experimental samples containing known concentrations of target species synthetic DNA), suggesting additional caution is warranted when estimating biomass from water samples with low concentrations of eDNA. Such findings contribute to 
the growing body of evidence that qPCR-based quantification may be less than precise for QM-ZM eDNA samples, which are consistent with findings across numerous taxa (Yates et al. 2019).

\section{Droplet Digital PCR}

Droplet digital PCR (ddPCR; Hindson et al. 2011) is a technologically advanced form of qPCR, recognised for DNA quantification precision. With ddPCR, microfluidic circuits and oil-water interactions are employed to partition individual DNA molecules and qPCR reagents (e.g. polymerase, primers, hydrolysis probes, free nucleotides etc.) into individual oil droplets. During this process, tens of thousands of droplets are generated and each undergoes an individual PCR. The concentration of target DNA within a sample is calculated, based on the number of droplets that fluoresce at a set level (i.e. in which target DNA has undergone amplification) relative to droplets that do not fluoresce (and, hence, lacked target DNA). This approach is a direct and more accurate method for quantifying DNA than "analogue" qPCR (i.e. conducted on a standard qPCR instrument with DNA concentrations estimated using standard curves) and is less susceptible to inhibitor-induced false negatives when eDNA concentrations are very low (Doi et al. 2015), which is commonly the case. Recent grey literature details the novel application of ddPCR for QM-ZM eDNA surveillance.

In a pilot study, Watts (2020) used the QM-ZM specific assay DRE16S (Gingera et al. 2017) in conjunction with a modified Corbicula assay (Cowart et al. 2018) to survey for ZM and Asian clams. Filtered water samples were collected at docks and boat ramps at six lakes in the north-eastern US across the following ZM and Corbicula infestation gradient: absent (i.e. control site), recently eradicated, transient, non-viable, newly identified and known. For ZM, detection success varied amongst sampling sites and months; the greatest detection success was observed in lakes with larger populations and when sampling occurred during the month of May (i.e. spring). The latter finding contrasts with previous evidence which suggested mid-summer (July; Sepulveda et al. 2019) and/ or autumn sampling (Peñarrubia et al. 2016; Gingera et al. 2017) provided the best QM-ZM eDNA detection success. Observed discordance across studies may be due to differences in sampling effort, where replication has been shown to significantly influence the probability of QM-ZM eDNA detection across seasons (Sepulveda et al. 2019).

Devlin and Youngbull (2019), employing a newly-developed portable instrument, also reported on the use of ddPCR to detect QM-ZM eDNA. The authors used Gingera et al. (2017) DRE16S primers, but incorporated a novel probe (Table 3). Interestingly, during a survey for QM-ZM in Lake Mead (AZ and NV, US), the study discovered that QM-ZM eDNA could be detected in near real-time by directly assaying lake water (i.e. no filtration or centrifugation of water samples; no purification, isolation or concentration of eDNA). However, direct assay results may not be indicative of outcomes in other waters, as Lake Mead represents an extremely infested location where QM-ZM eDNA may be in atypically high concentrations (i.e. readily detectable without the need to concentrate). 


\section{High-throughput sequencing}

High-throughput sequencing (HTS) is a modern technology in which numerous targets (e.g. samples, genes, DNA fragments, species) can be simultaneously sequenced, generating greater amounts of DNA data in shorter time frames, all while reducing sequencing costs. In eDNA studies, metabarcoding approaches are often used alongside HTS (in a multi-step process) to rapidly and bioinformatically identify the DNA (i.e. species) present in an environmental sample (Fig. 2). During the first step, DNA is typically amplified using cPCR and taxonomically broad "universal" barcoding or metabarcoding primers (Hebert et al. 2003; Taberlet et al. 2012). The obtained amplicons are subsequently sequenced or "read" via HTS and the resulting sequence data are then cross-referenced against either an existing DNA database (i.e. NCBI's GenBank, Barcode of Life Database (BOLD)) or a custom made DNA database. Using these databases and complex bioinformatic analyses, sequences (i.e. amplified DNA) can then be identified to species or higher taxonomic levels depending on the quality and taxonomic comprehensiveness of the reference databases. Metabarcoding presents unique challenges to eDNA analysis and interpretation. It is subject to losses in detection sensitivity (e.g. PCR amplification bias), increased risks of false-positive results (e.g. via contamination induced by HTS tag-hopping) and requires robust experimental evaluation (Zinger et al. 2019).

Metabarcoding HTS methods have been successfully applied to QM-ZM eDNA surveillance efforts, where several surveillance objectives have been met using a variety of primers (Table 3). For example, $\mathrm{CO} I$ metabarcoding primers, designed to generically target metazoans (Leray et al. 2013) and/or marine invertebrates (Geller et al. 2013), have been used to specifically detect ZM (Ardura et al. 2017) or QM eDNA (Blackman et al. 2020a) and to detect QM-ZM eDNA in community-wide surveys (Mychek-Londer et al. 2020). Metabarcoding primers targeting $18 \mathrm{~S}$ and designed to detect crustaceans, molluscs and tunicates (Zhan et al. 2013), have also been used alongside HTS to detect AIS at freshwater ports, revealing the presence of QM (Brown et al. 2016). Blackman et al. (2020a) report two important HTS findings from knowninfested waters: 1) an increase in distance between sampling (i.e. the point of eDNA collection) and the source population negatively influenced QM eDNA concentrations and 2) HTS underperformed in comparison to simultaneously employed speciesspecific cPCR and qPCR (Table 3), where QM detection was 86\% and 100\% successful, respectively. The latter finding was especially true in low density populations. The observation that HTS was less sensitive than species-specific qPCR is consistent with other studies (Lacoursière-Roussel et al. 2016b; Harper et al. 2018; Bylemans et al. 2019). Nevertheless, the relatively low performance of HTS in Blackman et al. (2020a) may be due to the use of a universal primer that presumably targets most animal groups (metazoans), but was not specifically designed for molluscs and, as a result, may preferentially amplify DNA from other, more abundant species and/or other species whose DNA exhibits better matches to the primer sequence. Thus, in the following paragraphs, we detail the development and use of more-specific HTS metabarcodes 
(e.g. mollusc-specific, bivalve-specific, QM-ZM-specific), which may provide better QM-ZM eDNA results.

Klymus et al. (2017) developed metabarcoding primers for specific use in AIS HTS efforts targeting molluscs (i.e. bivalves - or mussels and clams - and snails). To begin, the authors investigated the discriminatory power of three DNA regions (mitochondrial COI and $16 \mathrm{~S}$ and nuclear 28S) to detect and discriminate 19 invasive/potentially-invasive snail and bivalve species of concern within the Great Lakes Region. The most suitable region was 16S. Of the two primer sets subsequently developed, MOL16S (Table 3) was intended for use in molluscs, including QM-ZM. Performance of MOL16S was first evaluated using an experimental "mock community" eDNA sample, in which a solution was created containing a mixture of targeted DNA templates at known concentrations. The authors assessed the interaction of PCR amplification bias and amplicon/sequence read abundance. Amplification bias is described as the tendency of a primer to preferentially amplify ("detect") the DNA of certain species over others. The bias, which can impact HTS results, is largely due to nucleotide mismatch between the DNA sequence of the primers and the complimentary DNA regions of different targeted species (Piñol et al. 2014). The authors found that the number of observed sequence reads for a species correlated well with initial DNA concentrations. Thus, in eDNA surveys, HTS data may be useful for semi-quantitative purposes, providing rough estimations of the relative abundance/biomass of a target species. When the authors later deployed their technique in Great Lakes waters, MOL16S proved to be less specific than anticipated and, additionally, amplified DNA from non-targeted groups including oligochaete worms, rotifers and bryozoans. However, because sequences from different species can be parsed within HTS, the presence of QM-ZM could still be discerned, with the HTS eDNA effort still outperforming visual surveys. Snyder et al. (2020) later used HTS and MOL16S to successfully monitor for QM-ZM in holding-tank waters in bait shops in the Great Lakes Region.

Prié et al. (2020) also developed bivalve-specific HTS metabaroding primers, targeting $16 \mathrm{~S}$ in the orders Unionida (Unio01) and Venerida (Vene01). Primer Vene01 (Table 3) was designed such that members of the Dreissenidae family, including QM$\mathrm{ZM}$, would also be amplified and detected. Field samples from predominantly French lotic systems proved that Vene01 could successfully detect QM eDNA. The HTS primer provided evidence supporting a wider distribution and expanded invasion, for $\mathrm{QM}$ in that region.

Even greater metabarcoding specificity was achieved in Marshall and Stepien (2019). Here, the authors developed two HTS COI primer sets (COIA and COIB), which were designed to detect QM-ZM, as well as four other Dreissena species. The primers were additionally useful in discriminating amongst haplotypes within those species. Experimental tests, based on mock community samples, showed that COIA (Table 3) outperformed COIB. Consequently, the authors solely present HTS results from aquaria trials and field sampling using COIA. Ultimately, the authors were able to successfully assess QM-ZM species composition, relative abundance and population genetic diversity using eDNA samples and their newly-developed HTS method. Not 
only were HTS read counts for the two species well-correlated with known QM-ZM biomass, the approach also produced QM and ZM haplotype reads proportional to the haplotypic representation found in local populations of the two species. The aquaria trials produced two interesting results concerning HTS-based biomass estimations. First, HTS read abundance best matched known biomass after an acclimatisation period of 7-14 days. Second and similar to field-based findings in Amberg et al. (2019), aquaria trial evidence from this study further indicated that QM-ZM biomass may be best estimated using water samples collected near the bottom rather than at the surface.

\section{Loop-mediated isothermal amplification}

Technologies like cPCR, qPCR, ddPCR and HTS all achieve DNA amplification via thermal cycling and, thus, require instruments capable of rapid, cyclical heating and cooling. This is a significant limitation for in situ eDNA surveys, especially eDNA surveys in remote, inaccessible locations where it may be difficult to transport and power thermal-cycling equipment. A more field-friendly option - capable of providing point-of-collection results (Stedtfeld et al. 2012) and, thus, minimising delays in AIS surveillance (Merkes 2020) - may be found in loop-mediated isothermal amplification (LAMP; Notomi et al. 2000). Here, amplification occurs at a single temperature using a unique polymerase and three sets of specially designed primers, termed forward and backward inner primers (FIP and BIP), loop primers (LF and LB) and outer primers (F3 and B3). The unique polymerase, used in LAMP, is highly tolerant of amplification inhibitors (Koloren et al. 2011). This attribute makes LAMP appealing for eDNA samples, where inhibitors are especially challenging and can lead to amplification failure in PCR-based techniques. Yet, studies have found LAMP assays to be roughly $10 \times$ less sensitive than qPCR (Bühlmann et al. 2013; Waliullah et al. 2019) and may be unable to detect the very low concentrations of DNA typically observed in eDNA samples. Increased sample volume may provide a trade-off here. For example, with LAMP, potentially larger (and dirtier) volumes of water can be processed (i.e. filtered and extracted), without losing sensitivity due to inhibition. This could potentially allow for an increase in the capture and concentration of available eDNA and, thus, improve LAMP-based detection probability.

Williams et al. (2017) is the only publication to have successfully demonstrated, via lab and field trials, a QM-ZM eDNA LAMP capability. The authors developed three novel assays (Table 3) and investigated whether filtration and subsequent DNA extraction impacted the sensitivity of their LAMP-based approach. These are important investigations because LAMP is often used to directly amplify "crude" samples with minimal (if any) pre-processing (e.g. Stedtfeld et al. 2014; Maranhao et al. 2020). However and as mentioned above, eDNA samples typically undergo filtration (and subsequent DNA extraction) before amplification. These steps serve to concentrate target DNA, but coincidentally concentrate inhibitors as well. Performance was evaluated across sites with known and variable levels of QM-ZM infestation (i.e. high- vs. lowdensity populations) and where eDNA samples were collected across multiple seasons 
(including spawning season). In high-density situations (i.e. in large populations or during the spawning season), the authors found that neither filtration nor extraction was required to successfully detect QM-ZM using LAMP. In fact, the authors demonstrated that direct and PCR-free amplification of QM-ZM eDNA could be achieved at the point of collection in less than 90 min using a handheld, battery-operated LAMP device (Gene-Z; Stedtfeld et al. 2012). However, the greatest detection sensitivity was achieved when eDNA samples underwent both filtration and DNA extraction before being amplified with LAMP. This was particularly true for low-density populations, where filtration likely helped to concentrate DNA. Inhibition did not appear to be problematic for LAMP-based QM-ZM detection in these situations. Despite these successes, the incorporation of filtration and DNA extraction steps may decrease the fieldfriendliness of LAMP by requiring transport of additional equipment and reagents.

\section{Target type}

The vast majority of eDNA sampling endeavours, especially those involving QM-ZM, have relied on assays targeting short fragments of mtDNA (but see, Lance and Carr 2012; Peñarrubia et al. 2016; Williams et al. 2017). Mitochondrial DNA has dominated the field for two main reasons. One reason is that vast amounts of online sequence data exist for mtDNA. These readily accessible data make it easier to design effective eDNA assays that meet criteria for inclusivity (detect all genetic variants of target locus in species) and specificity (detect target taxa only). A second reason mtDNA is so popular in molecular-based surveys is that multiple lines of evidence have led to generalisations that multi-copy, membrane-bound mtDNA exists in the environment at higher concentrations and for longer periods than single-copy nuclear DNA (nuDNA) and/ or single-copy RNA (Thomsen and Willerslev 2015). Evidence also exists to suggest the same trends occur for short molecular fragments as compared to long molecular fragments (e.g. Jo et al. 2017). Ultimately this means that short mtDNA targets are appealing for use in eDNA endeavours because they are easier to detect. Yet, if lower concentration, longer fragments are subject to greater degradation and decay, perhaps these types of targets provide greater potential to selectively detect more contemporary signals, thus providing stronger indications that a living individual was recently present in the sampled system (Barnes and Turner 2016; Bista et al. 2017; Cristescu 2019). Growing evidence, however, reveals that, across these various types of molecular targets, patterns in deposition and degradation (which, in turn, influence abundance, persistence and detectability) are more complex than previous generalisations would suggest (e.g. Bylemans et al. 2018b; Harrison et al. 2019; Wood et al. 2020). Still, interest remains in how each of these unique molecular targets can be used, individually and in complement, to address various different surveillance objectives, including improved spatio-temporal inferences regarding distribution and time since deposition (hereafter, age). Very recent evidence provided by Marshall et al. (2021) suggests more accurate estimates of age can be achieved in molecular-based QM-ZM detection signals when surveys simultaneously employ both eDNA and eRNA. 
In fact, Marshall et al. (2021) investigated a number of pertinent questions related to the use of various molecular targets in qPCR-based QM-ZM detection and revealed profound new insights. Here, experiments were conducted in which aquaria samples were analysed for a combination of six different QM-ZM molecular targets (Table 3). These targets represented both the nuclear and mitochondrial genomes, and allowed for comparisons of different fragment lengths (i.e. short vs. long), eDNA vs. eRNA and messenger RNA (mRNA) vs. ribosomal (rRNA). To assess patterns in abundance, degradation and detectability across time, aquaria sampling occurred at intervals covering 0 and 4-240 $\mathrm{h}$ after QM-ZM removal. All targets were analysed, separately, as eDNA and as eRNA. To obtain separate eRNA data, eRNA extraction methods were used, with an additional reverse transcription PCR step added to the typical eDNA workflow. Marshall et al. (2021) concluded that they were better able to estimate the age of environmental genetic material when they combined both eDNA and eRNA and investigated the ratio of degradation between the two. Other important observations include: 1) similar to eDNA, eRNA concentrations can be positively associated with QM-ZM abundance across nuclear and mitochondrial genomes, 2) decay constants were similar for short (75-169 bp) vs. long (251 and 341 bp) gene targets/ fragments, 3) multi-copy rRNA genes (mitochondrial $16 \mathrm{~S}$ rRNA and nuclear $18 \mathrm{~S}$ rRNA) may improve detection in low density situations due to observed higher concentrations (and longer persistence after QM-ZM removal) and 4) mitosis-associated $\mathrm{H} 2 \mathrm{~B}$ mRNA provides a useful eRNA target for assessing the recent presence ( $<24 \mathrm{hrs}$ ) of live QM-ZM.

These QM-ZM specific experimental findings are in contrast to those of Wood et al. (2020). They conducted similar aquaria-based decay rate experiments in another AIS (a marine polychaete worm) and found (using ddPCR) that eRNA only remained detectable in aquaria samples within $14 \mathrm{~h}$ of target-organism removal, while eDNA persisted for much longer (up to $94 \mathrm{~h}$ after organism removal). Importantly, however, Wood et al. (2020) attributed these differences to initial eDNA/eRNA concentrations (i.e. shed rates), as opposed to any difference in decay rates, which were not found to be significantly different. Still, in both Marshall et al. (2021) and Wood et al. (2020), eRNA was found to persist at unexpectedly long intervals. For QM-ZM eRNA targets, the decay rates (presented as model-derived, log-linear per hour constants) ranged from -0.0561 to -0.0735 ( \pm 0.0025 ), equating to eRNA half-lives between 8.84 to $13.54 \mathrm{~h}$ (Marshall et al. 2021). It is possible that the experimental aquaria lacked natural bacterial communities and perhaps this helps explain the unexpectedly long intervals of observed eRNA persistence. Bacterial communities are known to contribute significantly to eDNA degradation (Nielsen et al. 2007; Lance et al. 2017, Zulkefli et al. 2019; Saito and Doi 2020) likely via enzymatic and metabolic activity (Finkel and Kolter 2001; Vorkapic et al. 2016; Al-Wahaibi et al. 2019). Thus, observed results may not reflect the rate of decay in natural systems where degradation may be expedited and/or more severe and/or where environmental conditions may further influence the fate of different molecular targets (e.g. see Harrison et al. 2019). Differences aside, evidence from Wood et al. (2020) suggests that tank biofilms may act as accumulators 
of "legacy" eDNA and eRNA (detectable up to 21 days post-organism-removal). This has important implications for QM-ZM monitoring efforts, especially those focused on assessing successful decontamination of ballast/bilge tanks. If legacy genetic material exists in biofilms of decontaminated tanks, this may lead to positive detections of QM-ZM across extended periods of time, even when QM-ZM are no longer present and/or viable.

\section{Summary, including paths forward and critical remaining gaps}

A robust suite of sensitive molecular-based methods has been used to successfully monitor invasive QM-ZM in North American waters and elsewhere. As such, more than 20 QM-ZM eDNA reports (in both peer-reviewed and grey literature) were reviewed herein, spanning a decade's worth of research, development and implementation. Approaches for eDNA-based QM-ZM surveillance have evolved from simple cPCR to cutting edge ddPCR and HTS (Fig. 1). Although eDNA sampling has been the pioneering focus of most molecular-based QM-ZM monitoring endeavours, recent eRNA findings suggest that exciting new avenues are on the horizon, in which eDNA and eRNA can be used together to advance spatio-temporal inferences. Despite much progress (Table 1), a number of critical scientific and applied gaps require resolution. We close this review by discussing ways in which the QM-ZM field can move forward by utilising existing recommendations for optimised best practices, while also highlighting critical remaining gaps in need of attention.

\section{Assay/Metabarcode choice}

Detection success and accuracy of results, can depend heavily on assay and/or HTS primer choice (e.g. Wilcox et al. 2013; Elbrecht et al. 2019). Although a wide variety of assays and primers are available for use in molecular-based QM-ZM survey efforts (Table 3), variable levels of validation and efficiency have been reported for each. A consensus to utilise only the best (i.e. most specific and sensitive) of these assays would benefit QM-ZM management and surveillance programmes by making results not only more reliable, but also more directly comparable. Findings from Sepulveda et al. (2020a) can be used as a guide in this respect, assisting future surveyors in the right direction for probe-based qPCR assay selection. Assay selection could be further assisted by the evaluation criteria recently outlined in Thalinger et al. (2020). Here, assays designed by Gingera et al. (2017), De Ventura et al. (2017) and Williams et al. (2017) have already been objectively identified as reliable. According to the supplementary data in Thalinger et al. (2020), the assays reached levels 3 and 4 out of a 5-level rating scale, in which minimum criteria covering 14 basic lab and field validation steps had been "essentially" or "substantially" demonstrated. This rating ultimately means that these assays are ready for field application, but are not fully operational and, thus, may limit the interpretations of non-detection results (e.g. at level 3, it is impossible to tell 
if negatives are false-negatives) and/or may require additional steps to validate positive detections (e.g. sequencing amplicons from positive samples).

Based on Sepulveda et al. (2020a) and Thalinger et al. (2020), we recommend the use of DRE16S (Gingera et al. 2017; Table 3) as a first choice for qPCR-based QMZM eDNA surveillance. We note, however, that the use of multiple assays targeting different gene regions improves detection success and accuracy (Lance and Guan 2019; Sepulveda et al. 2020a, b). Surveyors employ additional (non-16S) assays from the list of reliable choices in Sepulveda et al. (2020a) and Thalinger et al. (2020).

To our knowledge, similar evaluation criteria do not exist for HTS metabarcodes (but see, for example, methods used in Bylemans et al. 2018a and Elbrecht et al. 2019). Comparative evaluations of available QM-ZM-relevant metabarcoding primers are still needed. As such, round-robin tests akin to those in Sepulveda et al. (2020a) should be used to identify the most reliable and effective metabarcoding primers for HTS-based QM-ZM eDNA endeavours.

\section{Sampling effort}

As with all AIS survey methods, molecular-based surveys are susceptible to imperfect detection. Field and lab replicates are known to improve eDNA detection probabilities (Ficetola et al. 2015; Furlan et al. 2016; Willoughby et al. 2016). Sepulveda et al. (2019) found this to be true in QM-ZM, where occupancy modelling indicated that substantial field sampling is required to obtain high probabilities of detection, but with variable effort required depending on timing (i.e. QM-ZM life-cycle dependent, seasonal sampling). Synthesis of reviewed materials suggests that detection success may be improved by sampling during (Sepulveda et al. 2019) and/or after (Peñarrubia et al. 2016; Gingera et al. 2017) the spawning season, near the bottom of deep waters (Amberg and Merkes 2016; Amberg et al. 2019; Marshall and Stepien 2019) and where eDNA/eRNA particles are likely to accumulate (Amberg and Merkes 2016; Amberg et al. 2019). Sites of accumulation may not coincide with optimal QM-ZM habitat and may, instead, reflect environmental patterns of transport and settlement (Amberg and Merkes 2016; Amberg et al. 2019; Shogren et al. 2019).

\section{Field portable instruments (and PCR inhibition)}

A primary goal in QM-ZM surveillance is early detection and rapid response. Yet, most eDNA surveys have relied on laboratory-based workflows, instrumentation and analyses, which contributes to delays in results. The adoption of field portable and/ or rapid detection devices will likely improve the ability to implement on-site QMZM surveillance, thereby decreasing time-to-results, even in remote and/or widely dispersed locations. Several field-friendly instruments currently exist to potentially remedy these issues and thus improve immediacy, yet all appear to suffer some form of inadequacy, most often observed via low sensitivity (as influenced by PCR inhibition). For example, rapid detection may be possible with the handheld Franklin portable 
qPCR instrument (Biomeme, Philadelphia, PA). Here, eDNA results can be generated in $<1 \mathrm{~h}$. Yet, high false negative detection rates have been observed (Sepulveda et al. 2018), with additional evidence to suggest that optimisation may be required for samples in which PCR inhibitors are present (Sepulveda et al. 2018; Thomas et al. 2019). PCR inhibition is expected to be less problematic in ddPCR (e.g. Hoshino and Inagaki 2012) and in LAMP (e.g. Koloren et al. 2011). Yet, Devlin and Youngbull (2019) hypothesised that, when using a field-portable ddPCR instrument (DNA Tracker), "entrained organic matter" may have led to a false positive QM-ZM detection (via chimerisation) in non-infested waters. When Williams et al. (2017) investigated the use of a hand-held, battery operated LAMP device (Gene-Z; Stedtfeld et al. 2014), PCR inhibition did not appear to be a specific issue for QM-ZM surveillance. In fact, LAMP has been proven useful for rapid, onsite surveillance of other AIS in highrisk pathways, even with novice users (Merkes 2020). Yet, as demonstrated elsewhere (Bühlmann et al. 2013; Waliullah et al. 2019), Williams et al. (2017) observed poor performance of LAMP in settings where eDNA concentrations were low, indicating a trade-off between inhibitor tolerance and lowered sensitivity. These studies cumulatively indicate that methods to combat PCR inhibition are needed to better meet management priorities for accurate and reliable early detection.

\section{Quantification accuracy}

Several lab- and field-based studies report an observed correlation between known QM-ZM abundance and qPCR-based (Peñarrubia et al. 2016; De Ventura et al. 2017) or HTS-based (Klymus et al. 2017; Marshall and Stepien 2019) measurements (i.e. concentrations) of eDNA and/or eRNA (Marshall et al. 2021). Yet, the ability to precisely quantify QM-ZM eDNA and/or accurately interpret eDNA concentrations for abundance purposes has been called into question by at least two publications, including one in which controlled samples had been experimentally spiked with synthetic DNA at known concentrations (Sepulveda et al. 2020a) and another in which environmental factors were observed to complicate patterns in correlation between eDNA concentration and QM-ZM density (Shogren et al. 2019). Even amongst those QM-ZM studies that found correlation, two provided critical caveats regarding the precision and reliability of these estimates, citing potential complications arising from spawning activity and potential veliger presence (Peñarrubia et al. 2016; De Ventura et al. 2017). Moreover, such imprecision in eDNA-based quantification is not unique to QM-ZM. Similar findings have been observed across various systems and numerous taxa, with multiple explanations provided to account for observed variance in correlation and discrepancies in quantification accuracy. Explanations are typically complex and synergistic, but often include factors, such as PCR inhibition (e.g. McKee et al. 2015; Sigsgaard et al. 2015), choice and biases in different sampling and/or processing methodologies (e.g. Lacoursière-Roussel et al. 2016a; Hinlo et al. 2017), variability in eDNA deposition and degradation (e.g. Jo et al. 2020) and environmental and/or ecological effects (e.g. Barnes et al. 2014; Strickler et al. 2015). A recent meta-analysis 
revealed that correlations between quantification measures (i.e. eDNA concentrations and known abundance) were substantially and significantly stronger in experimental lab and/or artificial pond environments than in natural systems (Yates et al. 2019). Together these observations suggest that eDNA-based abundance estimates are prone to error and require additional investigation followed by subsequent optimisation. Until improvements are made, eDNA data can currently only provide - with some reliability - rough, semi-quantitative assessments of QM-ZM abundance (e.g. on a scale from very rare to extremely common).

Although no easy and straightforward solutions exist to immediately resolve these challenges in quantification, we see two paths forward. First, investigators should compare the performance of qPCR-based estimates to ddPCR-based estimates (as in, for example, Nathan et al. 2014; Doi et al. 2015) using high-performing QM-ZM assays (e.g. see results in Sepulveda et al. 2020a; Thalinger et al. 2020). When compared to qPCR, ddPCR should provide more precise, more consistent and more reproducible quantification of eDNA (even in the presence of inhibitors) as it utilises direct, absolute measurements not reliant on potentially fallible standard curves (although, note: similar to sampling replication, technical replication improves qPCR quantification; Mauvisseau et al. 2019). Yet, while ddPCR may present a technical solution for improved quantification accuracy, it still cannot remedy the inconsistencies and/or variability observed in the actual relationship between eDNA concentration and QM-ZM abundance, which often results from ecological and environmental factors. Thus, it will be necessary to not only utilise more precise instrumentation (and/or technical approaches), but also continue to investigate QM-ZM eDNA dynamics, especially dynamics in natural settings. This combination of refinements could lead to increased quantification precision and interpretation, possibly resulting in the ability to better assess eDNA survey data, both in terms of QM-ZM infestation levels and in terms of management successes (e.g. eradication efforts, where successful removal should equate to decreases in eDNA concentration). For such advancements to be effective, surveyors must take into consideration the fate of eDNA, including rates of shed, decay and degradation.

\section{Degradation in natural settings}

Degradation findings from laboratory-based aquaria experiments suggest that, amongst the markers studied to date, $\mathrm{H} 2 B$ mRNA provides the best eRNA marker for finer spatiotemporal QM-ZM assessments, narrowing the window of detection to $<24 \mathrm{~h}$ (Marshall et al. 2021). The same experiment provided evidence that the eDNA:eRNA ratio is a helpful predictor of time since deposition, demonstrating the advantage of using both eDNA and eRNA simultaneously (Marshall et al. 2021). Quantification accuracies aside (see discussion above), future studies should evaluate these findings in outdoor mesocosm settings, as even Marshall et al. (2021) suggests lab-based experiments may oversimplify the fate of eDNA and eRNA in more natural environmental conditions. De Ventura et al. (2017) called for these types of experiments and findings from Shogren et al. (2019) indicate that environmental conditions influence 
the fate (i.e. dispersion, retention and degradation) of molecular targets. We echo the recommendations of two recent publications (one review, Harrison et al. 2019 and one meta-analysis, Yates et al. 2019) and suggest that QM-ZM degradation experiments must be conducted in more natural environments before knowledge can be applied to real-world, field surveys. We also suggest that veliger presence must be controlled in these outdoor experiments; DNA within whole, microscopic organisms does not behave (i.e. degrade) the same as eDNA shed from adult mussels and may confound decay rate observations. A better understanding of the ecology of eDNA (including physical attributes and abiotic/ biotic interactions and fate; Barnes and Turner 2016) in real field settings and for improved quantification will benefit QM-ZM surveillance efforts tremendously by helping to reduce error and uncertainty in the interpretation of eDNA and/or eRNA data.

\section{Translating eDNA survey results into AIS management action}

Dreissenids pose severe risks to invaded waters and exhibit an exceptional ability to colonise new locations. Thus, proactive eDNA surveillance has been recommended to combat the spread of QM-ZM, in the hope that early detection and rapid response will prohibit colonisation (United States Department of Interior 2017). For this to be effective, AIS managers must be able to trust the outcomes of eDNA surveys and must be able to translate eDNA results into actionable responses. This represents an area of contention. Despite the efforts of eDNA experts to improve confidence in eDNA results via developments in QA-QC measures (Goldberg et al. 2016) and careful design of eDNA assays (Klymus et al. 2020a), managers may still be reluctant to adopt eDNA approaches for surveillance and management purposes. Much of the reluctance can be attributed to perceived uncertainty in eDNA detection capabilities and, specifically, a fear of "false-positive" detections unsupported by visual survey methods (Jerde et al. 2021).

Darling et al. (2021) suggests this perceived uncertainty is due to unrealistic expectations, a disregard for the low-sensitivity often exhibited by conventional survey methods (which potentially makes them inadequate for confirming the results of extremely sensitive eDNA approaches) and poorly defined eDNA terminology. In fact, Sepulveda et al. (2020c) demonstrates that eDNA methods are mature and scientifically-defensible, with well-established protocols for preventing, detecting and quantifying detection errors (e.g. false positives, contamination). While clearly susceptible to imperfect detection (as is the case with all AIS surveillance methods), Sepulveda et al. (2020c) suggests the problem with eDNA is not the validity of the method. Instead, what prevents adoption of eDNA into AIS policy and decision-making processes is a lack of pre-defined frameworks for integration, which incorporates risks and uncertainties. Together, Darling et al. (2021) and Sepulveda et al. (2020c) suggest that greater collaboration is needed between eDNA practitioners and resource managers. There is a need to involve eDNA surveillance end-users (e.g. natural resource managers, AIS decision-makers, other stakeholders) in eDNA study design, in which these end-users provide input to jointly formulate a decision-support framework. According 
to the guidance of Sepulveda et al. (2020c) and Darling et al. (2021), these frameworks should outline - in advance of eDNA sampling - criteria for discerning positive eDNA samples and subsequent action, expectations for critical QA-QC, jointly defined terminology (especially, false positives) and communication plans. These criteria should take into consideration the limitations inherent with eDNA surveillance (and conventional methods), as well as levels of confidence and/or risk acceptable by both parties. For an example of how to achieve this, see Sepulveda et al. (2020c).

Practitioners can also increase confidence by following minimum reporting guidelines. This means reporting the occurrence and subsequent handling of contamination issues (Sepulveda et al. 2020b). It also means reporting observed limits of detection and quantification (Bustin et al. 2009; Goldberg et al. 2016; Klymus et al. 2020a, b). These data allow for critical evaluations of the quality and integrity of eDNA methods, results and interpretations. Managers, interested in eDNA monitoring, should employ qualified, knowledgeable eDNA labs. Evidence suggests eDNA results are impacted by lab expertise and are most reliable (repeatable and reproducible) when practitioners are familiar with appropriate eDNA methodology and utilise high-performing assays (Hosler et al. 2017; Sepulveda et al. 2020a). Jerde (2021) outlines six essential criteria for evaluating AIS eDNA surveillance outcomes, which managers may find useful for assessing the strength of eDNA detections and for taking management action.

\section{Conclusions}

Adherence to the optimised guidance outlined above will serve to improve and standardise molecular-based QM-ZM surveillance efforts across studies. Yet, until specific challenges are overcome, inferences beyond simple presence/absence will remain limited. As such, efforts to address critical remaining gaps are essential for advancements in the interpretation of molecular-based survey data. With continued investigation and experimentation, we may be able to further refine the levels and kinds of inference possible and, hopefully, through enhanced knowledge and improved sensitivity and reliability, provide increasingly useful information to better meet management objectives. Given the negative impacts resulting from QM-ZM invasions and the relative ease with which the species can be spread, it is likely that both species will continue to be at the forefront of developments in this field.

\section{Acknowledgements}

We express appreciation to J. Crossland, X. Guan, D. Lindsay, Y. Passamaneck, W. T. Slack, H. Theel, D. Walter and N. Winstead for helpful reviews of the manuscript and associated glossary. We also thank C. Merkes for contributing to an early version of the loop-mediated isothermal amplification sub-section. A debt of gratitude is owed to two anonymous reviewers whose comments substantially improved the final product. 
Permission was granted by the Chief of Engineers to publish this information. The views expressed are those of the authors and do not necessarily represent those of the U.S. Army Corps of Engineers. The use of trade, product or firm names in this paper is for descriptive purposes only and does not imply endorsement by the U.S. Government.

Funding for this study was provided by the U.S. Army Corps of Engineers Aquatic Plant Control Program.

\section{References}

Al-Wahaibi ASM, Lapinska E, Rajarajan N, Dobretsov S, Upstill-Goddard R, Burgess JG (2019) Secretion of DNases by marine bacteria: A culture based and bioinformatics approach. Frontiers in Microbiology 10: e969. https://doi.org/10.3389/fmicb.2019.00969

Amberg JJ, Merkes CM (2016) Environmental DNA mapping of zebra mussel populations. Legislative-Citizen Commission on Minnesota Resources.

Amberg JJ, Merkes CM, Stott W, Rees CB, Erickson RA (2019) Environmental DNA as a tool to help inform zebra mussel, Dreissena polymorpha, management in inland lakes. Management of Biological Invasions 10: 96-110. https://doi.org/10.3391/mbi.2019.10.1.06

Ardura A, Zaiko A, Borrell YJ, Samuiloviene A, Garcia-Vazquez E (2017) Novel tools for early detection of a global aquatic invasive, the zebra mussel Dreissena polymorpha. Aquatic Conservation: Marine and Freshwater Ecosystems 27: 165-176. https://doi.org/10.1002/aqc.2655

Arya M, Shergill IS, Williamson M, Gommersall L, Arya N, Patel HR (2005) Basic principles of real-time quantitative PCR. Expert Review of Molecular Diagnostics 5: 209-219. https://doi.org/10.1586/14737159.5.2.209

Bae S, Wuertz S (2009) Discrimination of viable and dead fecal Bacteroidales bacteria by quantitative PCR with propidium monoazide. Applied and Environmental Microbiology 75: 2940-2944. https://doi.org/10.1128/AEM.01333-08

Baines SB, Fisher NS, Cole JJ (2007) Dissolved organic matter and persistence of the invasive zebra mussel (Dreissena polymorpha) under low food conditions. Limnology and Oceanography 52: 70-78. https://doi.org/10.4319/lo.2007.52.1.0070

Barnes MA, Turner CR (2016) The ecology of environmental DNA and implications for conservation genetics. Conservation Genetics 17: 1-17. https://doi.org/10.1007/s10592-0150775-4

Barnes MA, Turner CR, Jerde CL, Renshaw MA, Chadderton WL, Lodge DM (2014) Environmental conditions influence eDNA persistence in aquatic systems. Environmental Science and Technology 48: 1819-1827. https://doi.org/10.1021/es404734p

Berkman PA, Garton DW, Haltuch MA, Kennedy GW, Febo LR (2000) Habitat shift in invading species: zebra and quagga mussel population characteristics on shallow soft substrates. Biological Invasions 2: 1-6. https://doi.org/10.1023/A:1010088925713

Bista I, Carvalho G, Walsh K, Seymour M, Hajibabaei M, Lallias D, Christmas M, Creer S (2017) Annual time-series analysis of aqueous eDNA reveals ecologically relevant dynamics of lake ecosystem biodiversity. Nature Communications 8: e14087. https://doi. org/10.1038/ncomms 14087 
Blackman RC, Ling KKS, Harper LR, Shum P, Hänfling B, Lawson-Handley L (2020a) Targeted and passive environmental DNA approaches outperform established methods for detection of quagga mussels, Dreissena rostriformis bugensis in flowing water. Biorxiv 2020.01.07.890731. https://doi.org/10.1101/2020.01.07.890731

Blackman R, Benucci M, Donnelly R, Hänfling B, Harper LR, Sellers GS, Lawson Handley L (2020b) Simple, sensitive and species-specific assays for detecting quagga and zebra mussels (Dreissena rostriformis bugensis and D. polymorpha) using environmental DNA. Management of Biological Invasions 11: 218-236. https://doi.org/10.3391/mbi.2020.11.2.04

Bollens S, Rollwagen-Bollens G, Goldberg C (2015) Enhanced monitoring and investigation of the spread and potential impact of aquatic invasive mussels in the Columbia River Basin, with special reference to mitigation and placement of boat cleaning stations. Bonneville Power Administration Technology Innovations Program Report No. 276.

Bronnenhuber JE, Wilson CC (2013) Combining species-specific COI primers with environmental DNA analysis for targeted detection of rare freshwater species. Conservation Genetics Resources 5: 971-975. https://doi.org/10.1007/s12686-013-9946-0

Brown EA, Chain FJJ, Zhan A, MacIssac HJ, Cristescu ME (2016) Early detection of aquatic invaders using metabarcoding reveals a high number of non-indigenous species in Canadian ports. Diversity and Distributions 22: 1045-1059. https://doi.org/10.1111/ddi.12465

Bühlmann A, Pothier JF, Rezzonico F, Smits THM, Andreou M, Boonham N, Duffy B, Frey JE (2013) Erwinia amylovora loop-mediated isothermal amplification (LAMP) assay for rapid pathogen detection and on-site diagnosis of fire blight. Journal of Microbiological Methods 92: 332-339. https://doi.org/10.1016/j.mimet.2012.12.017

Bustin SA, Benes V, Garson JA, Hellemans J, Huggett J, Kubista M, Mueller R, Nolan T, Pfaffl MW, Shipley GL, Vandesompele J, Wittwer CT (2009) The MIQE guidelines: Minimum information for publication of quantitative real-time PCR experiments. Clinical Chemistry 55: 611-622. https://doi.org/10.1373/clinchem.2008.112797

Bylemans J, Gleeson DM, Hardy CM, Furlan E (2018a) Toward an ecoregion scale evaluation of eDNA metabarcoding primers: A case study for the freshwater fish biodiversity of the Murray-Darling Basin (Australia). Ecology and Evolution 8: 8697-8712. https://doi. org/10.1002/ece3.4387

Bylemans J, Furlan EM, Gleeson DM, Hardy CM, Duncan RP (2018b) Does size matter? An experimental evaluation of the relative abundance and decay rates in environmental DNA. Environmental Science Technology 52: 6408-6416. https://doi.org/10.1021/acs. est. $8 \mathrm{~b} 01071$

Bylemans J, Gleeson DM, Duncan RP, Hardy CM, Furlan EM (2019) A performance evaluation of targeted eDNA and eDNA metabarcoding analyses for freshwater fishes. Environmental DNA 1: 402-414. https://doi.org/10.1002/edn3.41

Carmon J, Keele J, Pucherelli SF, Hosler D (2014) PCR detection of quagga mussel intracellular DNA and dissolved DNA. Bureau of Reclamation Technical Memorandum No. 8668220-14-12.

Carraro L, Stauffer JB, Altermatt F (2020) How to design optimal eDNA sampling strategies for biomonitoring in river networks. Environmental DNA 3: 157-172. https://doi. org/10.1002/edn3.137 
Carraro L, Hartikainen H, Jokela J, Bertuzzo E, Rinaldo A (2018) Estimating species distribution and abundance in river networks using environmental DNA. Proceedings of the National Academy of Sciences of the United States 115: 11724-11729. https://doi. org/10.1073/pnas.1813843115

Claxton WT, Boulding EG (1998) A new molecular technique for identifying field collections of zebra mussel (Dreissena polymorpha) and quagga mussel (Dreissena bugensis) veliger larvae applied to eastern Lake Erie, Lake Ontario, and Lake Simcoe. Canadian Journal of Zoology 76: 194-198. https://doi.org/10.1139/z97-175

Conte J, Potoczniak MJ, Tobe SS (2018) Using synthetic oligonucleotides as standards in probe-based qPCR. BioTechniques 64: 177-179. https://doi.org/10.2144/btn-2018-2000

Counihan TD, Bollens SM (2017) Early detection monitoring for larval dreissenid mussels: how much plankton sampling is enough? Environmental Monitoring and Assessment 189: e98. https://doi.org/10.1007/s10661-016-5737-x

Cowart D, Renshaw M, Gantz C, Umek J, Chandra S, Egan SP, Lodge DM, Larson ER (2018) Development and field validation of an environmental DNA (eDNA) assay for invasive clams of the genus Corbicula. Management of Biological Invasions 9: 27-37. https://doi. org/10.3391/mbi.2018.9.1.03

Cristescu ME (2019) Can environmental RNA revolutionize biodiversity science? Trends in Ecology and Evolution 34: 694-697. https://doi.org/10.1016/j.tree.2019.05.003

Darling JA, Jerde CL, Sepulveda AJ (2021) What do you mean by false positive? Environmental DNA. https://doi.org/10.1002/edn3.194

De Ventura L, Kopp K, Seppälä K, Jokela J (2017) Tracing the quagga mussel invasion along the Rhine river system using eDNA markers: early detection and surveillance of invasive zebra and quagga mussels. Management of Biological Invasions 8: 101-112. https://doi. org/10.3391/mbi.2017.8.1.10

Devlin S, Youngbull C (2019) Near real-time molecular detection of invasive dreissenid mussel contamination of watercraft. United States Fish and Wildlife Report No. F17AP00981.

Doi H, Uchii K, Takahara T, Matsuhashi S, Yamanaka H, Minamoto T (2015) Use of droplet digital PCR for estimation of fish abundance and biomass in environmental DNA surveys. PLoS ONE 10: e0122763. https://doi.org/10.1371/journal.pone.0122763

Doll A (2018) Occurrence and survival of zebra mussel (Dreissena polymorpha) veliger larvae in residual water transported by recreational watercraft. Thesis. University of Minnesota, Twin Cities.

Egan SP, Grey E, Olds B, Feder JL, Ruggiero ST, Tanner CE, Lodge DM (2015) Rapid molecular detection of invasive species in ballast and harbor water by integrating environmental DNA and light transmission spectroscopy. Environmental Science and Technology 49: 4113-4121. https://doi.org/10.1021/es5058659

Egan SP, Barnes MA, Hwang C-T, Mahon AR, Feder JL, Ruggiero ST, Tanner CE, Lodge DM (2013) Rapid invasive species detection by combining environmental DNA with light transmission spectroscopy. Conservation Letters 6: 402-409. https://doi.org/10.1111/conl.12017

Elbrecht V, Braukmann TWA, Ivanova NV, Prosser SWJ, Hajibabaei M, Wright M, Zakharov EV, Hebert PDN, Steinke D (2019) Validation of COI metabarcoding primers for terrestrial arthropods. PeerJ 7: e7745. https://doi.org/10.7717/peerj.7745 
Ficetola GF, Miaud C, Pompanon F, Taberlet P (2008) Species detection using environmental DNA from water samples. Biology Letters 4: 423-425. https://doi.org/10.1098/ rsbl.2008.0118

Ficetola GF, Pansu J, Bonin A, Coissac E, Giguet-Covex C, De Barba M, Gielly L, Lopes CM, Boyer F, Pompanon F, Rayé G, Taberlet P (2015) Replication levels, false presences and the estimation of the presence/absence from eDNA metabarcoding data. Molecular Ecology Resources 15: 543-556. https://doi.org/10.1111/1755-0998.12338

Finkel SE, Kolter R (2001) DNA as a nutrient: Novel role for bacterial competence. Journal of Bacteriology 183: 6288-6293. https://doi.org/10.1128/JB.183.21.6288-6293.2001

Folmer O, Black M, Hoeh W, Lutz R, Vrijenhoek R (1994) DNA primers for amplification of mitochondrial cytochrome c oxidase subunit I from diverse metazoan invertebrates. Molecular Marine Biology and Biotechnology 3: 294-299.

Frischer ME, Kelly KL, Nierzwicki-Bauer SA (2012) Accuracy and reliability of Dreissena spp. Larvae detection by cross-polarized light microscopy, imaging flow cytometry, and polymerase chain reaction assays. Lake and Reservoir Management 28: 265-276. https://doi.or g/10.1080/07438141.2012.731027

Frischer ME, Hansen AS, Wyllie JA, Wimbush J, Murray J, Nierzwicki-Bauer SA (2002) Specific amplification of the $18 \mathrm{~S}$ rRNA gene as a method to detect zebra mussel (Dreissena polymorpha) larvae in plankton samples. Hydrobiologia 487: 33-44. https://doi. org/10.1023/A:1022971918673

Furlan EM, Gleeson D, Hardy CM, Duncan RP (2016) A framework for estimating the sensitivity of eDNA surveys. Molecular Ecology Resources 16: 641-654. https://doi. org/10.1111/1755-0998.12483

Geda SR, Lujan NK, Perkins M, Abernethy E, Sabaj MH, Gangloff M (2018) Multilocus phylogeny of the zebra mussel family Dreissenidae (Mollusca: Bivalvia) reveals a fourth Neotropical genus sister to all other genera. Molecular Phylogenetics and Evolution 127: 1020-1033. https://doi.org/10.1016/j.ympev.2018.07.009

Gelembiuk GW, May GE, Lee CE (2006) Phylogeography and systematics of zebra mussels and related species. Molecular Ecology 15: 1033-1050. https://doi.org/10.1111/j.1365294X.2006.02816.x

Geller J, Meyer C, Parker M, Hawk H (2013) Redesign of PCR primers for mitochondrial cytochrome c oxidase subunit I for marine invertebrates and application in all-taxa biotic surveys. Molecular Ecology Resources 13: 851-861. https://doi.org/10.1111/17550998.12138

Gingera T, Bajno R, Docker M, Reist J (2017) Environmental DNA as a detection tool for zebra mussels Dreissena polymorpha (Pallas, 1771) at the forefront of an invasion event in Lake Winnipeg, Manitoba, Canada. Management of Biological Invasions 8: 287-300. https://doi.org/10.3391/mbi.2017.8.3.03

Goldberg CS, Turner CR, Deiner K, Klymus KE, Thomsen PF, Murphy MA, Spear SF, McKee A, Oyler-McCance SJ, Cornman RS, Laramie MB, Mahon AR, Lance RF, Pilliod DS, Strickler KM, Waits LP, Fremier AK, Takahara T, Herder JE, Taberlet P (2016) Critical considerations for the application of environmental DNA methods to detect aquatic species. Methods in Ecology and Evolution 7: 1299-1307. https://doi.org/10.1111/2041210X.12595 
Graf D, Cummings K (2019) The freshwater mussels (Unionoida) of the world (and other less consequential bivalves). MUSSEL Project Web Site. http://www.mussel-project.net/ [Accessed 22 July 2020]

Harper LR, Handley LL, Hahn C, Boonham N, Rees HC, Gough KC, Lewis E, Adams IP, Brotherton P, Phillips S, Hänfling B (2018) Needle in a haystack? A comparison of eDNA metabarcoding and targeted qPCR for detection of the great crested newt (Triturus cristatus). Ecology and Evolution 8: 6330-6341. https://doi.org/10.1002/ece3.4013

Harrison JB, Sunday JM, Rogers SM (2019) Predicting the fate of eDNA in the environment and implications for studying biodiversity. Proceedings of the Royal Society B - Biological Sceinces 286(1915): e20191409. https://doi.org/10.1098/rspb.2019.1409

Hebert PDN, Muncaster BW, Mackie GL (1989) Ecological and genetic studies on Dreissena polymorpha (Pallas): a new mollusc in the Great Lakes. Canadian Journal of Fish and Aquatic Sciences 46: 1587-1591. https://doi.org/10.1139/f89-202

Hebert PDN, Cywinska A, Ball SL, deWaard JR (2003) Biological identifications through DNA barcodes. Proceedings of the Royal Society of B: Biological Sciences 270: 313-321. https://doi.org/10.1098/rspb.2002.2218

Heid CA, Stevens J, Livak KJ, Williams PM (1996) Real time quantitative PCR. Genome Resources 6: 986-994. https://doi.org/10.1101/gr.6.10.986

Herder JE, Valentini A, Bellemain E, Dejean T, van Delft JJCW, Thomsen PF, Taberlet P (2014) Environmental DNA - a review of the possible applications for the detection of (invasive) species. Stichting RAVON Report 2013-104.

Higgins SN, Zanden MJV (2010) What a difference a species makes: a meta-analysis of dreissenid mussel impacts on freshwater ecosystems. Ecological Monographs 80: 179-196. https://doi.org/10.1890/09-1249.1

Higuchi R, Dollinger G, Walsh P, Griffith R (1992) Simultaneous amplification and detection of specific DNA sequences. Nature Biotechnology 10: 413-417. https://doi.org/10.1038/ nbt0492-413

Higuchi R, Fockler C, Dollinger G, Watson R (1993) Kinetic PCR analysis: Real-time monitoring of DNA amplification reactions. Nature Biotechnology 11: 1026-1030. https://doi. org/10.1038/nbt0993-1026

Hindson BJ, Ness KD, Masquelier DA, Belgrader P, Heredia NJ, Makarewicz AJ, Bright IJ, Lucero MY, Hiddessen AL, Legler TC, Kitano TK, Hodel MR, Petersen JF, Wyatt PW, Steenblock ER, Shah PH, Bousse LJ, Troup CB, Mellen JC, Wittmann DK, Erndt NG, Cauley TH, Koehler RT, So AP, Dube S, Rose KA, Montesclaros L, Wang S, Stumbo DP, Hodges SP, Romine S, Milanovich FP, White HE, Regan JF, Karlin-Neumann GA, Hindson CM, Saxonov S, Colston BW (2011) High-throughput droplet digital PCR system for absolute quantitation of DNA copy number. Analytical Chemistry 83: 8604-8610. https://doi.org/10.1021/ac202028g

Hindson CM, Chevillet JR, Briggs HA, Gallichotte EN, Ruf IK, Hindson BJ, Vessella RL, Tewari M (2013) Absolute quantification by droplet digital PCR versus analog real-time PCR. Nature Methods 10: 1003-1005. https://doi.org/10.1038/nmeth.2633

Hinlo R, Gleeson D, Lintermans M, Furlan E (2017) Methods to maximise recovery of environmental DNA from water samples. PLoS ONE 12: e0179251. https://doi.org/10.1371/ journal.pone.0179251 
Hoshino T, Inagaki F (2012) Molecular quantification of environmental DNA using microfluidics and digital PCR. Systematic and Applied Microbiology 35: 390-395. https://doi. org/10.1016/j.syapm.2012.06.006

Hosler DM (2017) Where's the body? Dreissenid mussels, raw water testing, and the real value of environmental DNA. Management of Biological Invasions 8: 335-341. https://doi. org/10.3391/mbi.2017.8.3.07

Jerde CL (2021) Can we manage fisheries with the inherent uncertainty from eDNA? Journal of Fish Biology 98: 341-353. https://doi.org/10.1111/jfb.14218

Jerde CL, Mahon AR, Chadderton WL, Lodge DM (2011) "Sight-unseen" detection of rare aquatic species using environmental DNA. Conservation Letters 4: 150-157. https://doi. org/10.1111/j.1755-263X.2010.00158.x

Jo T, Arimoto M, Murakami H, Masuda R, Minamoto T (2020) Estimating shedding and decay rates of environmental nuclear DNA with relation to water temperature and biomass. Environmental DNA 2: 140-151. https://doi.org/10.1002/edn3.51

Jo T, Murakami H, Masuda R, Sakata M, Yamamoto S, Minamoto T (2017) Rapid degradation of longer DNA fragments enables the improved estimation of distribution and biomass using environmental DNA. Molecular Ecology Resources 17(6): e25-e33. https://doi. org/10.1111/1755-0998.12685

Johnson LE, Carlton JT (1996) Post-establishment spread in large-scale invasions: Dispersal mechanisms of the zebra mussel Dreissena Polymorpha. Ecology 77: 1686-1690. https:// doi.org/10.2307/2265774

Johnson LE, Padilla DK (1996) Geographic spread of exotic species: Ecological lessons and opportunities from the invasion of the zebra mussel Dreissena polymorpha. Biological Conservation 78: 23-33. https://doi.org/10.1016/0006-3207(96)00015-8

Johnson LE, Ricciardi A, Carlton JT (2001) Overland dispersal of aquatic invasive species: A risk assessment of transient recreational boating. Ecological Applications 11: 1789-1799. https://doi.org/10.1890/1051-0761(2001)011[1789:ODOAIS]2.0.CO;2

Johnson LE, Bossenbroek JM, Kraft CE (2006) Patterns and pathways in the post-establishment spread of non-indigenous aquatic species: The slowing invasion of North American inland lakes by the zebra mussel. Biological Invasions 8: 475-489. https://doi.org/10.1007/ s10530-005-6412-2

Karatayev AY, Burlakova LE, Padilla DK (2015) Zebra versus quagga mussels: a review of their spread, population dynamics, and ecosystem impacts. Hydrobiologia 746: 97-112. https://doi.org/10.1007/s10750-014-1901-x

Karatayev AY, Padilla DK, Minchin D, Boltovskoy D, Burlakova LE (2007) Changes in global economies and trade: the potential spread of exotic freshwater bivalves. Biological Invasions 9: 161-180. https://doi.org/10.1007/s10530-006-9013-9

Keele JA, Carmon J, Hosler D (2013) Polymerase Chain Reaction: Preparation and analysis of raw water samples for the detection of dreissenid mussels. Bureau of Reclamation Technical Memorandum No. 86-68220-13-13.

Kinzelbach R (1992) The main features of the phylogeny and dispersal of the zebra mussel Dreissena polymorpha. In: The zebra mussel Dreissena polymorpha: Ecology, Biological Monitoring and First Application in Water Quality Management. Gustav Fisher, Stuttgart, 5-17. 
Klymus KE, Marshall NT, Stepien CA (2017) Environmental DNA (eDNA) metabarcoding assays to detect invasive invertebrate species in the Great Lakes. PLoS ONE 12: e0177643. https://doi.org/10.1371/journal.pone.0177643

Klymus KE, Ruiz Ramos DV, Thompson NL, Richter CA (2020a) Development and testing of species-specific quantitative PCR assays for environmental DNA applications. Journal of Visualized Experiments 165: e61825. https://doi.org/10.3791/61825

Klymus KE, Merkes CM, Allison MJ, Goldberg CS, Helbing CC, Hunter ME, Jackson CA, Lance RF, Mangan AM, Monroe EM, Piaggio AJ, Stokdyk JP, Wilson CC, Richter CA (2020b) Reporting the limits of detection and quantification for environmental DNA assays. Environmental DNA 2: 271-282. https://doi.org/10.1002/edn3.29

Koloren Z, Sotiriadou I, Karanis P (2011) Investigations and comparative detection of Cryptosporidium species by microscopy, nested PCR and LAMP in water supplies of Ordu, Middle Black Sea, Turkey. Annals of Tropical Medicine Parasitology 105: 607-615. https://doi.org/10.1179/2047773211Y.0000000011

Lacoursière-Roussel A, Rosabal M, Bernatchez L (2016a) Estimating fish abundance and biomass from eDNA concentrations: Variability among capture methods and environmental conditions. Molecular Ecology Resources 16: 1401-1414. https://doi.org/10.1111/17550998.12522

Lacoursière-Roussel A, Dubois Y, Normandeau E, Bernatchez L, Adamowicz S (2016b) Improving herpetological surveys in eastern North America using the environmental DNA method. Genome 59: 991-1007. https://doi.org/10.1139/gen-2015-0218

Lance RF, Carr MR (2012) Detecting eDNA of invasive dreissenid mussels: Report on capital investment project. Aquatic Nuisance Species Research Program ERDC/TN ANSRP-12-2.

Lance RF, Guan X (2020) Variation in inhibitor effects on qPCR assays and implications for eDNA surveys. Canadian Journal of Fish and Aquatic Sciences 77: 23-33. https://doi. org/10.1139/cjfas-2018-0263

Lance RF, Klymus KE, Richter CA, Guan X, Farrington HL, Carr MR, Thompson N, Chapman DC, Baerwaldt KL (2017) Experimental observations on the decay of environmental DNA from bighead and silver carps. In: Wong WH, Piria M, Collas F, Simonović P, Tricarico E (Eds) Management of Invasive Species in Inland Waters. Management of Biological Invasions 8(3): 343-359. https://doi.org/10.3391/mbi.2017.8.3.08

Leray M, Yang JY, Meyer CP, Mills SC, Agudelo N, Ranwez V, Boehm JT, Machida RJ (2013) A new versatile primer set targeting a short fragment of the mitochondrial COI region for metabarcoding metazoan diversity: application for characterizing coral reef fish gut contents. Frontiers in Zoology 10: e34. https://doi.org/10.1186/1742-9994-10-34

Li F, Mahon AR, Barnes MA, Feder J, Lodge DM, Hwang C-T, Schafer R, Ruggiero ST, Tanner CE (2011) Quantitative and rapid DNA detection by laser transmission spectroscopy. PLoS ONE 6: e29224. https://doi.org/10.1371/journal.pone.0029224

Locklin JL, Corbitt DN, McMahon RF (2020) Settlement, density, survival and shell growth of zebra mussels, Dreissena polymorpha, in a recently invaded low latitude, warm water Texas reservoir. Aquatic Invasions 15: 408-434. https://doi.org/10.3391/ai.2020.15.3.04

Mächler E, Osathanunkul M, Altermatt F (2018) Shedding light on eDNA: neither natural levels of UV radiation nor the presence of a filter feeder affect eDNA-based detection 
of aquatic organisms. PLoS ONE 13: e0195529. https://doi.org/10.1371/journal. pone.0195529

Mahon AR, Barnes MA, Li F, Egan SP, Tanner CE, Ruggiero ST, Feder JL, Lodge DM (2013) DNA-based species detection capabilities using laser transmission spectroscopy. Journal of the Royal Society Interface 10(78): e20120637. https://doi.org/10.1098/rsif.2012.0637

Mahon AR, Barnes MA, Senapati S, Feder JL, Darling JA, Chang H-C, Lodge DM (2011) Molecular detection of invasive species in heterogeneous mixtures using a microfluidic carbon nanotube platform. PLoS ONE 6: e17280. https://doi.org/10.1371/journal. pone. 0017280

Maranhao A, Bhadra S, Paik I, Walker D, Ellington AD (2020) An improved and readily available version of Bst DNA Polymerase for LAMP, and applications to COVID-19 diagnostics. medRxiv: 10.02.20203356. https://doi.org/10.1101/2020.10.02.20203356

Marmiroli N, Maestri E (2007) Polymerase chain reaction (PCR). In: Picó Y (Ed.) Food Toxicants Analysis: Techniques, Strategies, and Development. Elsevier, The Netherlands, 147-187. https://doi.org/10.1016/B978-044452843-8/50007-9

Marsden JE, Spidle AP, May B (1996) Review of genetic studies of Dreissena spp. American Zoologist 36: 259-270. https://doi.org/10.1093/icb/36.3.259

Marshall NT, Stepien CA (2019) Invasion genetics from eDNA and thousands of larvae: A targeted metabarcoding assay that distinguishes species and population variation of zebra and quagga mussels. Ecology and Evolution 9: 3515-3538. https://doi.org/10.1002/ece3.4985

Marshall NT, Vanderploeg HA, Chaganti SR (2021) Environmental (e)RNA advances the reliability of eDNA by predicting its age. Scientific Reports 11: e2769. https://doi. org/10.1038/s41598-021-82205-4

Matthews J, Van der Velde G, Bij de Vaate A, Collas FPL, Koopman KR, Leuven RSEW (2014) Rapid range expansion of the invasive quagga mussel in relation to zebra mussel presence in The Netherlands and Western Europe. Biological Invasions 16: 23-42. https:// doi.org/10.1007/s10530-013-0498-8

Mauvisseau Q, Burian A, Gibson C, Brys R, Ramsey A, Sweet M (2019) Influence of accuracy, repeatability and detection probability in the reliability of species-specific eDNA based approaches. Scientific Reports 9: e580. https://doi.org/10.1038/s41598-018-37001-y

May B, Marsden JE (1992) Genetic identification and implications of another invasive species of dreissenid mussel in the Great Lakes. Canadian Journal of Fish and Aquatic Sciences 49: 1501-1506. https://doi.org/10.1139/f92-166

Merkes C (2020) In situ detection of multiple predominant species of Asian carp. US Patent No. US 2020/0115765 A1.

Mychek-Londer JG, Balasingham KD, Heath DD (2020) Using environmental DNA metabarcoding to map invasive and native invertebrates in two Great Lakes tributaries. Environmental DNA 20: 283-297. https://doi.org/10.1002/edn3.56

Nalepa TF, Schloesser DW [Eds] (2013) Quagga and Zebra Mussels: Biology, Impacts, and Control, $2^{\text {nd }}$ edn. CRC Press, Boca Raton, 815 pp. https://doi.org/10.1201/b15437

Nathan LM, Simmons M, Wegleitner BJ, Jerde CL, Mahon AR (2014) Quantifying environmental DNA signals for aquatic invasive species across multiple detection platforms. Environmental Science and Technology 48: 12800-12806. https://doi.org/10.1021/es5034052 
Nielsen KM, Johnsen PJ, Bensasson D, Daffonchio D (2007) Release and persistence of extracellular DNA in the environment. Environmental Biosafety Research 6: 37-53. https:// doi.org/10.1051/ebr:2007031

Nocker A, Sossa-Fernandez P, Burr MD, Camper AK (2007) Use of propidium monoazide for live/dead distinction in microbial ecology. Applied and Environmental Microbiology 73: 5111-5117. https://doi.org/10.1128/AEM.02987-06

Notomi T, Okayama H, Masubuchi H, Yonekawa T, Watanabe K, Amino N, Hase T (2000) Loop-mediated isothermal amplification of DNA. Nucleic Acids Research 28: e63. https:// doi.org/10.1093/nar/28.12.e63

Pawlowski J, Apothéloz-Perret-Gentil L, Altermatt F (2020) Environmental DNA: What's behind the term? Clarifying the terminology and recommendations for its future use in biomonitoring. Molecular Ecology 29: 4258-4264. https://doi.org/10.1111/mec.15643

Pedersen MW, Overballe-Petersen S, Ermini L, Sarkissian CD, Haile J, Hellstrom M, Spens J, Thomsen PF, Bohmann K, Cappellini E, Schnell IB, Wales NA, Carøe C, Campos PF, Schmidt AM, Gilbert MT, Hansen AJ, Orlando L, Willerslev E (2015) Ancient and modern environmental DNA. Philosophical transactions of the Royal Society B - Biological Sciences 370(1660): e20130383. https://doi.org/10.1098/rstb.2013.0383

Peñarrubia L, Alcaraz C, bij de Vaate A, Sanz N, Pla C, Vidal O, Viñas J (2016) Validated methodology for quantifying infestation levels of dreissenid mussels in environmental DNA (eDNA) samples. Scientific Reports 6: e39067. https://doi.org/10.1038/ srep39067

Peyer SM, McCarthy AJ, Lee CE (2009) Zebra mussels anchor byssal threads faster and tighter than quagga mussels in flow. Journal of Experimental Biology 212: 2027-2036. https:// doi.org/10.1242/jeb.028688

Pilliod DS, Goldberg CS, Arkle RS, Waits LP (2013) Estimating occupancy and abundance of stream amphibians using environmental DNA from filtered water samples. Canadian Journal of Fisheries and Aquatic Sciences. 70: 1123-1130. https://doi.org/10.1139/cjfas-2013-0047

Piñol J, Mir G, Gomez-Polo P, Agusti N (2014) Universal and blocking primer mismatches limit the use of high-throughput DNA sequencing for the quantitative metabarcoding of arthropods. Molecular Ecology Resources 15: 819-830. https://doi.org/10.1111/17550998.12355

Pochon X, Zaiko A, Fletcher LM, Laroche O, Wood SA (2017) Wanted dead or alive? Using metabarcoding of environmental DNA and RNA to distinguish living assemblages for biosecurity applications. PLoS ONE 12: e0187636. https://doi.org/10.1371/journal. pone.0187636

Prié V, Valentini A, Lopes-Lima M, Froufe E, Rocle M, Poulet N, Taberlet P, Dejean T (2020) Environmental DNA metabarcoding for freshwater bivalves biodiversity assessment: methods and results for the Western Palearctic (European sub-region). Hydrobiologia 848: 2931-2950. https://doi.org/10.1007/s10750-020-04260-8

QZAP [Quagga-Zebra Mussel Action Plan for Western Waters] (2010) Prepared by the Western Regional Panel on Aquatic Nuisance Species. Submitted to the Aquatic Nuisance Species Task Force. https://anstaskforce.gov/QZAP/QZAP_FINAL_Feb2010.pdf 
Ram JL, Palazzolo S (2008) Globalization of an aquatic pest: economic costs, ecological outcomes, and positive applications of zebra mussel invasions and expansions. Geography Compass 2: 1755-1776. https://doi.org/10.1111/j.1749-8198.2008.00168.x

Ricciardi A, Serrouya R, Whoriskey FG (1995) Aerial exposure tolerance of zebra and quagga mussels (Bivalvia: Dreissenidae): implications for overland dispersal. Canadian Journal of Fisheries and Aquatic Sciences 52: 470-477. https://doi.org/10.1139/f95-048

Rosenberg G, Ludyanskiy ML (1994) A nomenclatural review of Dreissena (Bivalvia: Dreissenidae), with identification of the quagga mussel as Dreissena bugensis. Canadian Journal of Fish and Aquatic Sciences 51: 1462-1673. https://doi.org/10.1139/f94-147

Saito T, Doi H (2020) Degradation modeling of water environmental DNA: Experiments on multiple DNA sources in pond and seawater. bioRxiv 2020.04.03.023283. https://doi. org/10.1101/2020.04.03.023283

Sansom BJ, Sassoubre LM (2017) Environmental DNA (eDNA) shedding and decay rates to model freshwater mussel eDNA transport in a river. Environmental Science and Technology 51: 14244-14253. https://doi.org/10.1021/acs.est.7b05199

Sepulveda AJ, Amberg JJ, Hanson E (2019) Using environmental DNA to extend the window of early detection for dreissenid mussels. Management of Biological Invasions 10: 342-358. https://doi.org/10.3391/mbi.2019.10.2.09

Sepulveda AJ, Nelson NM, Jerde CL, Luikart G (2020c) Are environmental DNA methods ready for aquatic invasive species management? Trends in Ecology and Evolution 35: 668-678. https://doi.org/10.1016/j.tree.2020.03.011

Sepulveda AJ, Hutchins PR, Forstchen M, Mckeefry MN, Swigris AM (2020b) The elephant in the lab (and field): Contamination in aquatic environmental DNA studies. Frontiers in Ecology and Evolution 8: e609973. [12 pp.] https://doi.org/10.3389/fevo.2020.609973

Sepulveda AJ, Hutchins PR, Massengill RL, Dunker KJ, Barnes MA (2018) Tradeoffs of a portable, field-based environmental DNA platform for detecting invasive northern pike (Esox lucius) in Alaska. Management of Biological Invasions 9: 253-258. https://doi. org/10.3391/mbi.2018.9.3.07

Sepulveda AJ, Hutchins PR, Jackson C, Ostberg C, Laramie MB, Amberg J, Counihan T, Hoegh A, Pilliod DS (2020a) A round-robin evaluation of the repeatability and reproducibility of environmental DNA assays for dreissenid mussels. Environmental DNA 2(4): 446-459. https://doi.org/10.1002/edn3.68

Shogren AJ, Tank JL, Egan SP, Bolster D, Riis T (2019) Riverine distribution of mussel environmental DNA reflects a balance among density, transport, and removal processes. Freshwater Biology 64: 1467-1479. https://doi.org/10.1111/fwb.13319

Snider J, Moore J, Volkoff M, Byron S (2014) Assessment of quagga mussel (Dreissena bugensis) veliger survival under thermal, temporal and emersion conditions simulating overland transport. California Fish and Game 100: 640-651.

Snyder MR, Stepien CA, Marshall NT, Scheppler HB, Black CL, Czajkowski KP (2020) Detecting aquatic invasive species in bait and pond stores with targeted environmental (e)DNA high-throughput sequencing metabarcode assays: Angler, retailer, and manager implications. Biological Conservation 245: e108430. [12 pp.] https://doi.org/10.1016/j. biocon.2020.108430 
Son M (2007) Native range of the zebra mussel and quagga mussel and new data on their invasions within the Ponto-Caspian Region. Aquatic Invasions 2: 174-184. https://doi. org/10.3391/ai.2007.2.3.4

Stedtfeld RD, Stedtfeld TM, Kronlein M, Seyrig G, Steffan RJ, Cupples AM, Hashsham SA (2014) DNA extraction-free quantification of Dehalococcoides spp. in groundwater using a hand-held device. Environmental Science and Technology 48: 13855-13863. https://doi. org/10.1021/es503472h

Stedtfeld RD, Tourlousse DM, Seyrig G, Stedtfeld TM, Kronlein M, Price S, Ahmad F, Gulari E, Tiedje JM, Hashsham SA (2012) Gene-Z: a device for point of care genetic testing using a smartphone. Lab on a Chip 12: 1454-1462. https://doi.org/10.1039/c2lc21226a

Stoeckel JA, Schneider DW, Soeken LA, Blodgett KD, Sparks RE (1997) Larval dynamics of a riverine metapopulation: implications for zebra mussel recruitment, dispersal and control in a large river system. Journal of North American Benthological Society 16: 586-601. https://doi.org/10.2307/1468146

Strickler KM, Fremier AK, Goldberg CS (2015) Quantifying effects of UV-B, temperature, and $\mathrm{pH}$ on eDNA degradation in aquatic microcosms. Biological Conservation 183: 85-92. https://doi.org/10.1016/j.biocon.2014.11.038

Taberlet P, Coissac E, Pompanon F, Brochmann C, Willerslev E (2012) Towards next-generation biodiversity assessment using DNA metabarcoding. Molecular Ecology 21: 20452050. https://doi.org/10.1111/j.1365-294X.2012.05470.x

Takahara T, Minamoto T, Yamanaka H, Doi H, Kawabata Z (2012) Estimation of fish biomass using environmental DNA. PLoS ONE 7: e35868. https://doi.org/10.1371/journal. pone. 0035868

Thalinger B, Deiner K, Harper LR, Rees HC, Blackman RC, Sint D, Traugott M, Goldberg CS, Bruce K (2020) A validation scale to determine the readiness of environmental DNA assays for routine species monitoring. BioRxiv 2020.04.27.063990. https://doi. org/10.1101/2020.04.27.063990

Thomas AC, Tank S, Nguyen PL, Ponce J, Sinnesael M, Goldberg CS (2020) A system for rapid eDNA detection of aquatic invasive species. Environmental DNA 2: 261-270. https:// doi.org/10.1002/edn3.25

Thomsen PF, Willerslev E (2015) Environmental DNA - An emerging tool in conservation for monitoring past and present biodiversity. Biological Conservation 183: 4-18. https://doi. org/10.1016/j.biocon.2014.11.019

Thomsen PF, Kielgast J, Iversen LL, Wiuf C, Rasmussen M, Gilbert MTP, Orlando L, Willerslev E (2012) Monitoring endangered freshwater biodiversity using environmental DNA. Molecular Ecology 21: 2565-2573. https://doi.org/10.1111/j.1365294X.2011.05418.x

Trebitz AS, Hatzenbuhler CL, Hoffman JC, Meredith CS, Peterson GS, Pilgrim EM, Barge J, Cotter AM, Wick M (2019) Dreissena veligers in western Lake Superior - inference from new low-density detection. Journal of Great Lakes Research 45: 691-699. https:// doi.org/10.1016/j.jglr.2019.03.013

Tucker C (2014) Development of a new quantitative PCR methodology to detect exotic mollusk invasions in freshwater. Thesis. Colorado State University, Pueblo. 
Turner CR, Barnes MA, Xu CCY, Jones SE, Jerde CL, Lodge DM (2014) Particle size distribution and optimal capture of aqueous macrobial eDNA. Methods in Ecology and Evolution 5: 676-684. https://doi.org/10.1111/2041-210X.12206

United States Department of Interior (2017) Safeguarding the west from invasive species: Actions to strengthen Federal, State, and Tribal coordination to address invasive mussels. https://www.doi.gov/sites/doi.gov/files/uploads/safeguarding_the_west_from_invasive_ species.pdf

United States Fish and Wildlife Service (2011) The $100^{\text {th }}$ Meridian Initiative: A strategic approach to prevent the westward spread of zebra mussels and other aquatic nuisance species. https://www.fws.gov/fisheries/ans/pdf_files/100thMeridian.pdf

Vorkapic D, Pressler K, Schild S (2016) Multi-faceted roles of extracellular DNA in bacterial physiology. Current Genetics 62: 71-79. https://doi.org/10.1007/s00294-015-0514-x

Waliullah S, Hudson O, Oliver JE, Brannen PM, Ji P, Ali ME (2019) Comparative analysis of different molecular and serological methods for detection of Xylella fastidiosa in blueberry. PLoS ONE 14: e0221903. https://doi.org/10.1371/journal.pone.0221903

Watts AW (2020) Invasive species detection in northeast regional lakes using environmental DNA (eDNA) - zebra mussel and Asian clam Pilot study 2019. University of New Hampshire.

Wilcox TM, Mckelvey KS, Young MK, Jane SF, Lowe WH, Whiteley AR, Schwartz MK (2013) Robust detection of rare species using environmental DNA: The importance of primer specificity. PloS ONE 8: e59520. https://doi.org/10.1371/journal.pone.0059520

Williams MR, Stedtfeld RD, Engle C, Salach P, Fakher U, Stedtfeld T, Dreelin E, Stevenson RJ, Latimore J, Hashsham SA (2017) Isothermal amplification of environmental DNA (eDNA) for direct field-based monitoring and laboratory confirmation of Dreissena sp. PLoS ONE 12: e0186462. https://doi.org/10.1371/journal.pone.0186462

Willoughby JR, Wijayawardena BK, Sundaram M, Swihart RK, DeWoody JA (2016) The importance of including imperfect detection models in eDNA experimental design. Molecular Ecology Resources 16: 837-844. https://doi.org/10.1111/1755-0998.12531

Wimbush J, Frischer ME, Zarzynski JW, Nierzwicki-Bauer SA (2009) Eradication of colonizing populations of zebra mussels (Dreissena polymorpha) by early detection and SCUBA removal: Lake George, NY. Aquatic Conservation: Marine and Freshwater Ecosystems 19: 703-713. https://doi.org/10.1002/aqc.1052

Wittwer CT, Herrmann MG, Moss AA, Rasmussen RP (1997) Continuous fluorescence monitoring of rapid cycle DNA amplification. Biotechniques 22: 130-138. https://doi. org/10.2144/97221bi01

Wood SA, Biessy L, Latchford JL, Zaiko A, von Ammon U, Audrezet F, Cristescu ME, Pochon X (2020) Release and degradation of environmental DNA and RNA in a marine system. Science of the Total Environment 704: e135314. https://doi.org/10.1016/j. scitotenv.2019.135314

Yates MC, Fraser DJ, Derry AM (2019) Meta-analysis supports further refinement of eDNA for monitoring aquatic species-specific abundance in nature. Environmental DNA 1: 5-13. https://doi.org/10.1002/edn3.7

Zhan A, Hulák M, Sylvester F, Huang X, Abebayo AA, Abbott CL, Adamowicz SJ, Heath DD, Cristescu ME, MacIsaac HJ (2013) High sensitivity of 454 pyrosequencing for detection 
of rare species in aquatic communities. Methods in Ecology and Evolution 4: 558-565. https://doi.org/10.1111/2041-210X.12037

Zinger L, Bonin A, Alsos IG, Bálint M, Bik H, Boyer F, Chariton AA, Creer S, Coissac E, Deagle BE, De Barba M, Dickie IA, Dumbrell AJ, Ficetola GF, Fierer N, Fumagalli L, Gilbert MTP, Jarman S, Jumpponen A, Kauserud H, Orlando L, Pansu J, Pawlowski J, Tedersoo L, Thomsen PF, Willerslev E, Taberlet P (2019) DNA metabarcoding-Need for robust experimental designs to draw sound ecological conclusions. Molecular Ecology 28: 1857-1862. https://doi.org/10.1111/mec.15060

Zulkefli NS, Kim KH, Hwang SJ (2019) Effects of microbial activity and environmental parameters on the degradation of extracellular environmental DNA from a eutrophic lake. International Journal of Environmental Research and Public Health 16(18): e3339. [15 pp.] https://doi.org/10.3390/ijerph16183339 